\title{
Análise de desempenho na geração de benefícios econômicos dos clubes de futebol brasileiros: $o$ uso do atleta como recurso estratégico e ativo intangível
}

Analysis of the performance in generating of economic benefits in Brazilian football clubs: the use of athlete as a strategic resource and intangible asset

El análisis de rendimiento en la generación de beneficios económicos de los clubes de fútbol brasileños: el uso del atleta como un recurso estratégico y activos intangibles

\section{Nadielli Maria dos Santos Galvão}

Mestra em Ciências Contábeis na Universidade Federal de Pernambuco

Professora Assistente da Universidade Federal de Sergipe

Endereço: Av. Ver. Olímpio Grande, $\mathrm{s} / \mathrm{n}$ - Porto

CEP: 49500-000 - Itabaiana/SE, Brasil

E-mail: profa.nadielligalvao@gmail.com

Telefone: (79) 99950-1992

\section{Jairo Simião Dornelas}

Doutor em Administração pela Universidade Federal do Rio Grande do Sul

Professor da Universidade Federal de Pernambuco

Endereço: Avenida dos Economistas - S/N, Cidade Universitária

CEP: 50670902 - Recife/ PE - Brasil

E-mail: jairo@ufpe.br

Telefone: (81) 2126-8368

Artigo recebido em 25/04/2016. Revisado por pares em 08/02/107. Reformulado em 08/03/2017. Recomendado para publicação em 09/04/2017 por Carlos Eduardo Facin Lavarda (Editor-Chefe). Publicado em 31/08/2017. 


\title{
Resumo
}

De acordo com a Visão Baseada em Recursos, as empresas investem em recursos estratégicos visando benefícios econômicos e vantagem competitiva. Na norma contábil os mesmos são considerados ativos intangíveis geradores de benefícios econômicos. O objetivo deste trabalho foi verificar o desempenho dos clubes de futebol brasileiros na utilização do atleta como ativo intangível e recurso estratégico para a geração de benefícios econômicos entre 2010 a 2013. Assim, adotou-se a análise envoltória de dados, cujo input foi considerado o investimento em atletas e outputs receitas, caixa e resultado. Os dados foram coletados nas demonstrações contábeis de 18 clubes extraídas dos sites das próprias organizações esportivas, federações estaduais ou dos diários oficiais dos estados onde atuam. Constatou-se que os clubes não são eficientes em gerar os benefícios, principalmente o superávit, sendo receitas a variável cujo alcance pelos clubes tem melhor desempenho.

Palavras-chave: Atletas; Ativo Intangível; Clubes de Futebol; Desempenho Organizacional; Visão Baseada em Recursos

\begin{abstract}
According to the Resource-Based View, companies invest in strategic resources for economic benefits and competitive advantage. In the accounting standard they are considered intangible assets that generate economic benefits. The objective of this study was to verify the performance of Brazilian soccer clubs in the use of the athlete as an intangible asset and strategic resource for the generation of economic benefits between 2010 and 2013. Thus, we adopted the data involution analysis, whose input Was considered the investment in athletes and outputs revenues, cash and income. The data were collected in the financial statements of 18 clubs extracted from the websites of the sports organizations themselves, state federations or the official diaries of the states where they operate. It was found that the clubs are not efficient in generating the benefits, mainly the surplus, being revenues the variable whose reach by the clubs perform better.
\end{abstract}

Keywords: Intangible Assets; Athletes; Organizational Performance; Soccer clubs

\section{Resumen}

De acuerdo con la visión basada en los recursos, las empresas invierten en recursos estratégicos destinados a beneficios económicos y ventajas competitivas. En la norma contable que se consideran activos intangibles que generan beneficios económicos. El objetivo de este estudio fue verificar el funcionamiento de los clubes de fútbol brasileños en el uso del atleta como activo intangible y recurso estratégico para la generación de beneficios económicos entre 2010 y 2013. Así, hemos adoptado el análisis envolvente de datos, cuya entrada fue la inversión en jugadores y salidas los ingresos, dinero y el resultado. Los datos fueron recogidos en los estados financieros de 18 clubes procedentes de los sitios web de los clubes, federaciones o boletines oficiales de los estados en los que operan. Se encontró que los clubes no son eficientes en la generación de beneficios, pero ingresos es la variable cuyo ámbito los clubes obtienen mejores resultados.

Palabras clave: Activos Intangibles; Atletas; Clubes de fútbol; Rendimiento de la Organización

\section{Introdução}

Inicialmente, os clubes eram considerados entidades sem fins lucrativos, no entanto, com o advento da Lei 9.615 de 1998, lhes foi dada a oportunidade de atuarem como organizações com fins lucrativos, nas quais os gestores deveriam focar a geração de lucros e o 
crescimento de receitas (PIRES, 1998). Assim, os clubes passaram a esperar que seus atletas passassem a gerar receitas, lucro e fluxo de caixa, tal qual um ativo organizacional (LOPES; DAVIS, 2006; CRUZ et al., 2010). Com isso, é possível identificar também as características de recursos estratégicos nos atletas, visto que estes permitem o alcance de vantagem competitiva. Tais recursos são o objeto de estudo da Visão Baseada em Recursos que busca identificar as diferenças existentes entre organizações diante da posse e gerenciamento dos recursos estratégicos de cada uma.

Do ponto de vista contábil, o Conselho Federal de Contabilidade (CFC) emitiu a Resolução 1.429 de 2013 que enquadra os atletas adquiridos através da cessão de direitos contratuais como ativo intangível, tratamento também dispensado ao atleta formado internamente. Ativos intangíveis também são comumente considerados um tipo de recurso estratégico para as organizações.

Porém, as organizações esportivas apresentam prejuízos sucessivos em seus demonstrativos contábeis, possuem alto endividamento explicitando fracos resultados financeiros, ao mesmo tempo que contabilizam altos investimentos realizados em jogadores. Esse contrassenso pode ser reflexo do baixo caixa gerado por essas entidades (GUINDANI et al., 2012; ITAÚ, 2015; ESPN, 2015), e da má percepção do gerenciamento dos investimentos em ativo intangível.

Este aspecto leva ao enunciado da questão que norteia esta pesquisa e que se configura como sendo: Qual o desempenho dos clubes de futebol que participaram da série A do campeonato brasileiro, na utilização do atleta como ativo intangível e recurso estratégico para a geração de benefícios econômicos, no período de 2010 a 2013 ?

Dessa forma, o objetivo da pesquisa converte-se em verificar o desempenho dos clubes de futebol brasileiro na utilização do atleta como ativo intangível e recurso estratégico para a geração de benefícios econômicos entre os períodos de 2010 a 2013.

A realização da pesquisa justifica-se por agregar à literatura contábil olhar contributivo para evidenciar o potencial de resultado financeiro que o investimento milionário na contratação de jogadores pode render para os clubes, trazendo também a visão dos gestores para o atleta como fonte de retornos econômicos e financeiros, conforme inspiram Sá e Zarko (2014).

Para fins práticos na área contábil, este trabalho pode trazer à tona uma discussão sobre a coerência da norma que indica a necessidade de contabilização dos atletas como ativos intangíveis. Já do ponto de vista da contabilidade gerencial, o trabalho reforça o papel da medição de desempenho nas organizações, como forma de auxiliar o gestor no que tange à tomada de decisão quanto ao investimento em ativos intangíveis.

O trabalho está dividido em cinco seções, sendo esta uma seção introdutória onde foi apresentado o contexto da pesquisa, a questão problema, os objetivos e a justificativa para realização do trabalho. A seção seguinte aborda a revisão de literatura com os conceitos necessários para uma compreensão do objeto de estudo do trabalho. A terceira seção apresenta a metodologia para realização da pesquisa, cujos resultados são apresentados e discutidos na quarta seção. A quinta e última seção abordam as conclusões do estudo, suas contribuições, limitações e propostas para pesquisas futuras.

\section{Revisão de Literatura}

Neste capítulo serão apresentados os conceitos utilizados para embasar este trabalho, passando pela linha teórica adotada, aspectos contábeis que norteiam o estudo, bem como a questão da análise de desempenho organizacional. 


\subsection{Visão Baseada em Recursos}

$\mathrm{Na}$ área organizacional importa, de fato, avaliar como a empresa gerencia seus recursos de forma que os objetivos empresariais sejam alcançados com a máxima eficiência. Para estudar este fato, surgiu a abordagem teórica conhecida como a visão baseada em recursos, mais conhecida na sua versão inglesa - resource based view (RBV) - propondo explicar as diferenças entre as organizações a partir dos recursos únicos e essenciais de cada uma (KRETZER; MENEZES, 2006).

Os recursos na RBV podem ser conceituados como qualquer elemento de uma determinada organização, sob a forma de ativos tangíveis e intangíveis (WENERFELT, 1984), que formam um reservatório básico à implementação de processos administrativos. A seu termo, Barney (1991) destaca a existência de três tipos de recursos em uma organização, os quais são conceituados e detalhados a seguir, bem como esquematizados na figura 1 .

Figura 1 - Recursos empresariais

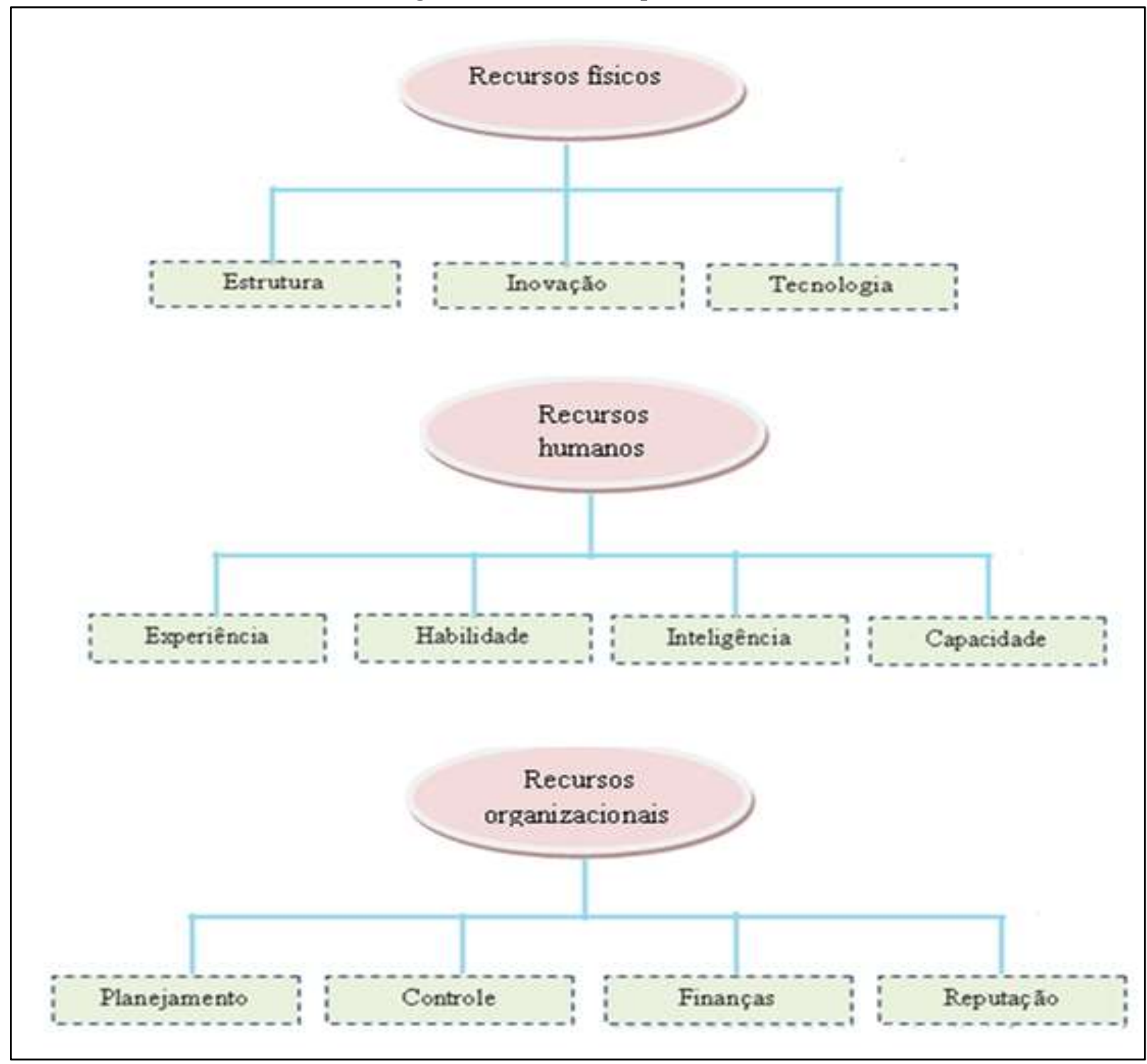

Fonte: Adaptado de Barney (1991).

Os recursos físicos estão relacionados à estrutura física, à inovação e à tecnologia 
organizacional. Elementos como realização de projetos, melhorias nas características dos produtos, arquitetura de software, bem como a localização geográfica da empresa, máquinas e instalações da produção e edificações podem ser considerados recursos físicos estratégicos (MINTZBERG, 2007).

O segundo grupo de recursos apontado por Barney (1991) é o de recursos humanos, os quais incluem a experiência e inteligência dos funcionários e gerentes da empresa. Carvalho et al. (2014) apontam que os recursos humanos têm sido o tipo de recurso mais citado como responsável pelo bom desempenho organizacional.

Por fim, os recursos organizacionais incluem a estrutura formal da empresa, os seus sistemas de planejamento, controle e coordenação, seus recursos financeiros, bem como as relações da firma com o ambiente externo. Dentro desse grupo também pode ser inserida a reputação da empresa.

No que se refere aos clubes de futebol, os jogadores têm sido considerados recursos essenciais para o alcance de vantagem competitiva e desempenho em campeonatos (FRANCK; NÜESCH; PIEPER, 2011; SILVA JÚNIOR; SALAZAR; FEITOSA, 2014), pois podem possuir certo potencial para geração de benefícios, enquadrando-se dentro dos aspectos de recursos estratégicos, vez que apresentam habilidades individuais que não podem ser facilmente imitadas e são controlados pelo clube, podendo apresentar a capacidade de gerar receitas e vantagem competitiva.

Tem-se ainda que, como os recursos estratégicos podem ser divididos em físicos, humanos e organizacionais, os atletas são considerados os recursos humanos cujas habilidades, estratégias, experiências, inteligências e capacidades são utilizadas para o sucesso competitivo do clube, mas também para a geração de benefícios econômicos.

Ademais, os atletas têm sido considerados como ativos intangíveis. Sobre esse tema debruça-se a próxima seção do trabalho.

\subsection{Aspectos Contábeis para os Atletas}

Os elementos patrimoniais podem ser resumidos em dois grupos: ativo e passivo (RUTHERFORD, 2003). Os ativos podem ser conceituados como itens controlados pela entidade, resultante de eventos passados dos quais se espera benefício econômico futuro (FINANCIAL ACCOUNTING STANDARDS BOARD n.3, 1974).

Ainda neste aspecto, existe um tipo específico de ativo denominado ativo intangível que de acordo com o Pronunciamento 04 do Comitê de Pronunciamentos Contábeis, editado em 2008 e revisado em 2010, não possui natureza física e monetária como as marcas, lista de clientes, patentes, licenças, direitos autorais, franquias, goodwill entre outros. Nesta visão também podem ser enquadrados os atletas nos clubes de futebol, conforme aponta a ITG 2003 (2012).

Tal norma contábil (ITG 2003) destaca que os valores pagos para adquirir os direitos contratuais dos atletas, bem como para renová-los e ainda pagamento de luvas é que devem ser contabilizados como ativos intangíveis. A norma ainda destaca que tais cifras contabilizadas no ativo devem ser amortizadas de acordo com o prazo contratual e no mínimo no final do exercício deve ser avaliada a possibilidade de recuperação do valor líquido contábil dos direitos contratuais de cada atleta.

Como benefícios econômicos esperados de um ativo intangível enquadram-se a expectativa de geração de fluxo de caixa ou equivalentes de caixa para a azienda (PEREZ; FAMÁ, 2006), bem como o potencial produtivo, quando o ativo é utilizado nas atividades operacionais da organização (CARVALHO; COSTA; OLIVEIRA, 2010). Ambas estas características são, a princípio, enquadráveis como associadas à gestão das carreiras dos atletas 
nos clubes.

Dois trabalhos que apresentam maior repercussão quanto ao tratamento dos atletas como ativos intangíveis são o de Amir e Livne (2005) e Foker (2005), os quais investigaram se os atletas possuem a característica de geração de benefícios econômicos para os clubes. Os resultados encontrados apontaram que os atletas são capazes de gerar receitas, lucros e caixa para as organizações esportivas, porém essa relação não foi tão significativa quanto o esperado.

Esses dois estudos fundamentaram os alicerces necessários para a realização da pesquisa realizada por Risalti e Verona (2013), em que os autores verificaram que o investimento em atletas visando à geração de receitas com bilheterias, foi um esforço que raramente funcionou no contexto italiano. Sendo assim, ficou frágil e questionável os resultados atingidos quando se deu tratamento de ativo intangível para os atletas.

No entanto insiste-se que ainda se faz necessário investigar se os clubes de futebol brasileiros têm sido eficientes em gerar os benefícios econômicos apontados como relacionados com o investimento em atletas, no caso ativo intangível. Para isso, faz-se necessário compreender o processo de medição do desempenho organizacional.

\subsection{Desempenho Organizacional}

A constante avaliação do desempenho organizacional é meritória, para que sejam realizados ajustes nas estratégias definidas, no comportamento e motivação dos funcionários e na utilização dos recursos disponíveis, visando à eficiência das operações da empresa (FORZA; SALVADOR, 2000). Sasson e Douglas (2006) assumem que o processo de análise do desempenho de uma empresa possui três componentes que são destacados na figura 2.

Figura 2 - Processo de análise de desempenho

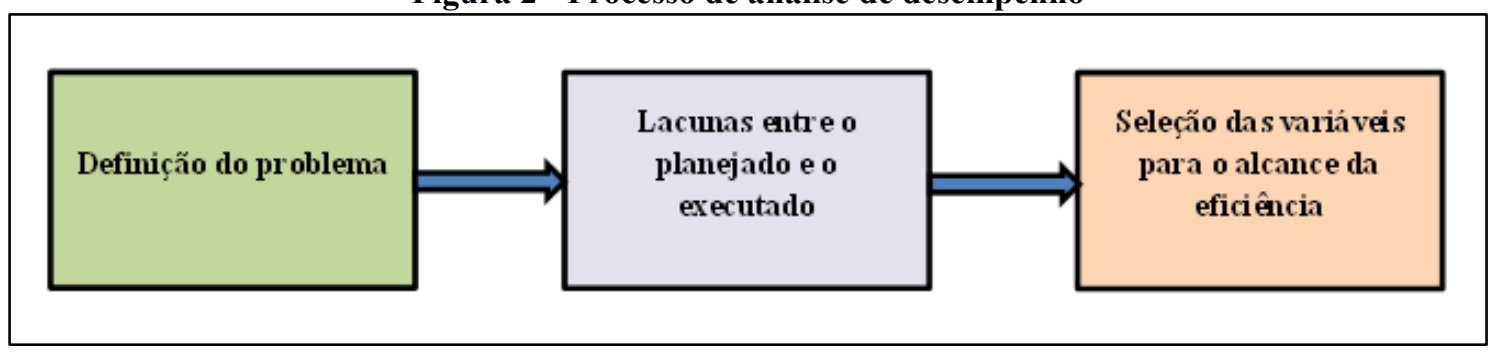

Fonte: Adaptado de Sasson e Douglas (2006)

Sendo assim, é preciso conhecer o quê se quer medir e como se irá medir. Para isso é necessário que o gestor conheça medidas e indicadores de desempenho organizacional, de forma que selecione aqueles que melhor se enquadrem na realidade da sua empresa.

Do ponto de vista da contabilidade gerencial é muito comum a utilização de indicadores econômico-financeiros que procuram evidenciar a situação de endividamento, liquidez e rentabilidade da organização. Alguns desses indicadores são destacados no quadro 1, os quais são extraídos dos dados apresentados nos demonstrativos das organizações.

Uma abordagem crescente para avaliação do desempenho está relacionada à utilização de métodos estatísticos e matemáticos, os quais, segundo Züge e Chaves Neto (1999), melhoram sensivelmente o processamento das informações chaves para a tomada de decisão empresarial, tornando-as mais embasadas e acertadas. Nesse ínterim, um tipo de modelo que tem sido bastante aplicado no processo de avaliação do desempenho organizacional é a análise envoltória de dados (NASCIMENTO et al., 2010). 


\begin{tabular}{|c|c|c|}
\hline Indicador & & \\
\hline $\begin{array}{l}\text { Liquidez } \\
\text { Imediata }\end{array}$ & $\frac{\text { Disponibilidades }}{\text { Passivo circulante }}$ & $\begin{array}{l}\text { Valor imediato para saldar } \\
\text { dívidas de curto prazo. }\end{array}$ \\
\hline $\begin{array}{l}\text { Liquidez } \\
\text { Corrente }\end{array}$ & $\frac{\text { Ativo circulante }}{\text { Passivo circulante }}$ & $\begin{array}{l}\text { Valor que a empresa dispõe } \\
\text { no ativo circulante para } \\
\text { saldar dívidas de curto prazo. }\end{array}$ \\
\hline Liquidez Seca & $\frac{\text { Ativo circulante }- \text { estoques }- \text { despesas antecipadas }}{\text { Passivo circulante }}$ & $\begin{array}{l}\text { Valor que a empresa dispõe } \\
\text { de disponibilidades e valores } \\
\text { a receber no curto prazo para } \\
\text { saldar dívidas do circulante. }\end{array}$ \\
\hline Liquidez geral & $\begin{array}{l}\text { Ativo circulante }+ \text { Ativo realizável a longo prazo } \\
\text { Passivo circulante }+ \text { Passivo realizável a longo prazo }\end{array}$ & $\begin{array}{l}\text { Valor que a empresa dispõe } \\
\text { de todos os ativos disponíveis } \\
\text { para pagamento de todos os } \\
\text { seus passivos. }\end{array}$ \\
\hline $\begin{array}{l}\text { Endividamento } \\
\text { Geral }\end{array}$ & $\frac{\text { Passivo total }}{\text { Passivo total }+ \text { Patrimônio líquido }}$ & $\begin{array}{l}\text { Expressa a porcentagem que } \\
\text { o endividamento representa } \\
\text { sobre os fundos totais. }\end{array}$ \\
\hline $\begin{array}{l}\text { Participação de } \\
\text { terceiros sobre } \\
\text { capital próprio }\end{array}$ & $\frac{\text { Passivo total }}{\text { Patrimônio líquido }}$ & $\begin{array}{l}\text { Expressa a porcentagem que } \\
\text { o endividamento representa } \\
\text { sobre o capital próprio. }\end{array}$ \\
\hline $\begin{array}{l}\text { Quociente de } \\
\text { composição do } \\
\text { endividamento }\end{array}$ & $\frac{\text { Passivo circulante }}{\text { Passivo total }}$ & $\begin{array}{l}\text { Representa a porcentagem } \\
\text { das dívidas de curto prazo } \\
\text { sobre o endividamento total. }\end{array}$ \\
\hline Giro do ativo & $\frac{\text { Receita com vendas }}{\text { Ativo total }}$ & $\begin{array}{l}\text { Indica o quanto a empresa } \\
\text { vendeu para cada } \\
\text { investimento realizado no } \\
\text { ativo. }\end{array}$ \\
\hline $\begin{array}{l}\text { Margem } \\
\text { líquida }\end{array}$ & $\frac{\text { Lucro líquido }}{\text { Vendas }}$ & $\begin{array}{l}\text { Apresenta quanto a empresa } \\
\text { tem de lucro para cada venda } \\
\text { realizada. }\end{array}$ \\
\hline $\begin{array}{l}\text { Retorno sobre } \\
\text { o Patrimônio } \\
\text { Líquido } \\
\end{array}$ & $\frac{\text { Lucro líquido }}{\text { Patrimônio Líquido }}$ & $\begin{array}{l}\text { Indica quanto a empresa } \\
\text { obteve de lucro em relação ao } \\
\text { capital próprio investido. }\end{array}$ \\
\hline $\begin{array}{l}\text { Rentabilidade } \\
\text { do ativo }\end{array}$ & $\frac{\text { Lucro líquido }}{\text { Ativo total }}$ & $\begin{array}{l}\text { Indica quanto a empresa } \\
\text { obteve de lucro em } \\
\text { decorrência do investimento } \\
\text { total em ativos. }\end{array}$ \\
\hline
\end{tabular}

Fonte: Adaptado de Iudícibus (2009) e Assaf Neto (2012).

\subsection{Análise Envoltória de Dados}

A análise envoltória de dados (Data Envelopment Analysis - DEA) tem sido considerada útil por apontar, dentro de uma amostra específica a ser estudada, os componentes que são eficientes na utilização de seus recursos para geração de determinados produtos (DINIZ, 2012).

A DEA encaixa-se no escopo da contabilidade gerencial, auxiliando-a no processo de medição de desempenho das empresas, verificando a eficiência na utilização de recursos para o alcance de determinadas metas e objetivos e concorrendo para definir indicadores de performance.

Em detalhe, a análise envoltória de dados apresenta-se como uma técnica de avaliação do desempenho de várias unidades operacionais (chamadas de decision making units - DMU), mediante o uso de entradas para a produção de saídas (MACEDO; CASA NOVA; ALMEIDA, 2009), que permite avaliar o grau de eficiência de várias DMU's levando em consideração os 
recursos disponíveis (entradas) e os resultados alcançados (saídas).

A partir do cálculo do índice de eficiência, é formada uma fronteira com as DMUs que obtiverem índices próximos de $1 \mathrm{e}$, abaixo dessa fronteira, será formada uma região com as DMUs consideradas não eficientes (DANTAS; BOENTE, 2011), já que quanto mais próximo o indicador de eficiência estiver de 1 , mais eficiente é a DMU na utilização dos recursos. $\mathrm{Na}$ figura 3 é possível verificar as DMUs que compõem uma fronteira de eficiência ( $a, b$ e c), bem como aquela considerada com baixo desempenho (i).

Figura 3 - Exemplo de fronteira de eficiência fornecida pela DEA

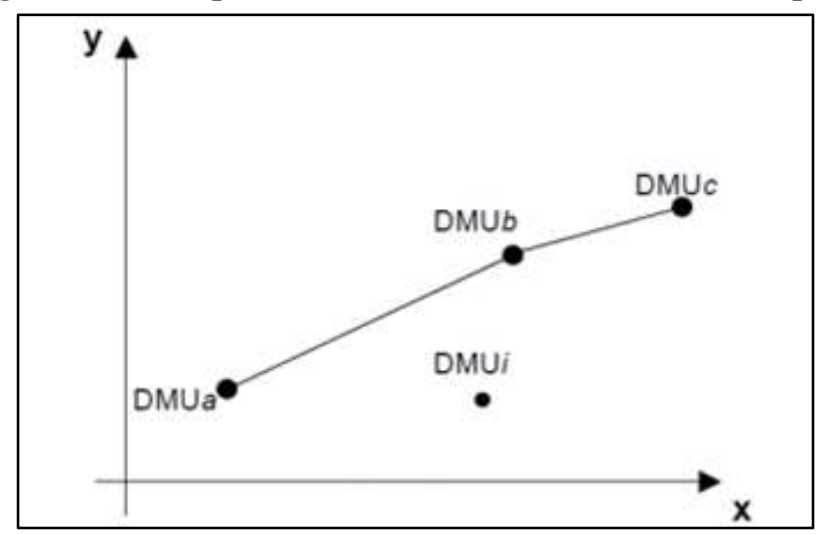

Fonte: Borges (2006, p.263)

Então, embora as DMUs a, b e c consumam distintos montantes de insumos e ofereçam produtos em quantidades diferentes, elas ocupam a mesma zona de fronteira de eficiência; no entanto, a DMU i está fora da fronteira, sendo considerada ineficiente em relação às demais (BORGES, 2006). Esse enredo, supõe-se, é similar entre os clubes de futebol.

Os dois modelos existentes na DEA segundo Mello et al. (2005) são:

a) O constant returns to scale (CRS) que trabalha com retornos constantes, em que qualquer variação nas entradas possui uma variação proporcional nas saídas;

b) O variable returns to scale (VRS) que descarta a proporcionalidade entre entradas e saídas, admitindo que DMUs que operam com baixos valores de entrada tenham retornos crescentes, enquanto DMUs que possuam altos valores de entrada obtenham retornos decrescentes.

Ambos os modelos podem ser orientados à entrada ou à saída. Quando orientados à entrada, deseja-se minimizar os recursos, porém mantendo o retorno constante. Já a orientação à saída permite uma maximização das saídas sem diminuir o total de entradas (GOMES; MELLO; LINS, 2004).

Ainda em relação à DEA, cita-se a análise da fronteira invertida que, de acordo com Giacomello e Oliveira (2014) informam a DMU, dentre aquelas consideradas eficientes, que apresentou melhor comportamento na utilização dos recursos para a obtenção de produtos.

Alguns estudos no contexto nacional utilizaram a técnica DEA para análise do desempenho dos clubes de futebol. Dentre eles, cita-se Pereira et al. (2015) que verificaram como a estrutura contábil do clube exerce influência em sua eficiência no alcance de pontos no ranking de clubes da CBF. Já Nascimento et al. (2015) investigaram a eficiência dos clubes em obter receitas (eficiência financeira), valor de mercado (eficiência econômica) e conquista de bons resultados (eficiência esportiva).

Ainda, resgata-se Dantas, Machado e Macedo (2015) que procuraram avaliar quais os fatores, tais como "Grau de Endividamento", "Títulos", "Divisão", "12 grandes clubes", "Acesso ou Libertadores", "Rebaixamento", "Aproveitamento de Pontos" e "Passivo a 
Descoberto", que determinam a eficiência dos clubes de futebol no Brasil. Os resultados apontaram que apenas "Títulos" e "Divisão" possuem alguma relação estatisticamente significativa com os indicadores analisados.

A fim de alcançar a proposta traçada neste trabalho de avaliação dos clubes de futebol, traçou-se um roteiro metodológico que será explanado na próxima seção deste trabalho.

\section{Procedimentos Metodológicos}

Este estudo, diante do problema e objetivos propostos, assume uma postura positivista pautando-se no método dedutivo. Teve como abordagem adotada a quantitativa, tratando-se de uma pesquisa descritiva.

Quanto à estratégia da pesquisa, usou-se a pesquisa documental, que se utiliza do exame de materiais que ainda não receberam um tratamento analítico, com o objetivo de fundamentar interpretações novas ou complementares sobre o que está sendo investigado, fazendo uso de fontes secundárias (LIMA, 2008).

Como critério para escolha dos clubes, foram selecionados, por conveniência, clubes de futebol brasileiro que participaram da série A do campeonato brasileiro, ao menos uma vez, entre 2005 a 2013, o que inclui clubes de diferentes portes e regiões. Os clubes de série A foram escolhidos, visto que constituem, supostamente, a elite do futebol brasileiro e, de acordo com Amir e Livne (2005), apresentam maiores investimentos em atletas profissionais, por figurarem na principal competição do futebol nacional. $\mathrm{O}$ ano de 2005 foi escolhido como inicial para delineamento da amostra, visto ser este o ano em que a Resolução CFC 1.005 admitiu o conceito de ativo intangível para os atletas dos clubes de futebol no Brasil.

Inicialmente, a amostra seria composta por 35 clubes, pois o objetivo era analisar o desempenho dos clubes em gerar receitas, fluxo de caixa e lucro a partir do investimento em atletas entre os anos de 2005 a 2013. Porém, como os clubes do futebol brasileiro não possuem uma tradição de divulgação de informações contábeis, realizou-se um corte no espaço temporal, o que reduziu o período de observação para os anos de 2010 a 2013, pontos críticos em que foi possível encontrar demonstrações contábeis de todos os clubes selecionados.

Assim, o trabalho pôde contar com os demonstrativos contábeis completos e em condições de suprir as necessidades desse estudo de apenas 18 clubes do estipulado inicialmente, conforme evidenciado no quadro 3.

Quadro 3 - Amostra final do estudo

\begin{tabular}{|c|c|c|c|}
\hline Clubes & Estado & Clubes & Estado \\
\hline Atlético & PR & Internacional & RS \\
\hline Botafogo & RJ & Náutico & PE \\
\hline Corinthians & SP & Palmeiras & SP \\
\hline Criciúma & SC & Ponte Preta & SP \\
\hline Figueirense & SC & Portuguesa & SP \\
\hline Flamengo & RJ & Santos & SP \\
\hline Fluminense & RJ & São Caetano & SP \\
\hline Goiás & GO & São Paulo & SP \\
\hline Grêmio & RS & Vasco da Gama & RJ \\
\hline
\end{tabular}

Fonte: elaboração própria.

A escolha de variáveis a analisar respeitou diretrizes de estudos anteriores, em especial as de Amir e Livne (2005) e Forker (2005), adequando-as à realidade pretendida nesse estudo, 
quanto à forma de apresentação dos itens nos demonstrativos contábeis dos clubes brasileiros. O quadro 4 apresenta as variáveis propostas, o objetivo de cada uma e a demonstração contábil de origem.

Quadro 4 - Definição operacional das variáveis selecionadas para o estudo

\begin{tabular}{|c|c|c|c|c|}
\hline $\begin{array}{l}\text { Tipo de } \\
\text { Variável }\end{array}$ & $\begin{array}{c}\text { Variável } \\
\text { (nome) }\end{array}$ & Fórmula & Objetivo & $\begin{array}{c}\text { Demonstração } \\
\text { Contábil de } \\
\text { origem }\end{array}$ \\
\hline Entrada & INVAI & Ativo Intangível (n) - Ativo Intangível (n-1) & $\begin{array}{l}\text { Verificar o quanto } \\
\text { se investiu em } \\
\text { ativo intangível } \\
\text { (atletas) no período } \\
\text { de um ano }\end{array}$ & $\begin{array}{c}\text { Balanço } \\
\text { patrimonial ou } \\
\text { suas notas } \\
\text { explicativas }\end{array}$ \\
\hline Saída & REC & $\begin{array}{c}\text { Receita com bilheteria + Receita com } \\
\text { transmissão de jogos + Receita com } \\
\text { patrocínio + Receita com venda de produtos } \\
\text { licenciados + Premiações em } \\
\text { campeonatos+receita com sócio-torcedor }\end{array}$ & $\begin{array}{l}\text { Verificar o total de } \\
\text { receita gerada pelo } \\
\text { clube no período }\end{array}$ & $\begin{array}{l}\text { Demonstração do } \\
\text { resultado }\end{array}$ \\
\hline Saída & FCX & Fluxo de caixa gerado no período & $\begin{array}{c}\text { Verificar a geração } \\
\text { de caixa no } \\
\text { período. O valor } \\
\text { será retirado na } \\
\text { demonstração de } \\
\text { fluxo de caixa }\end{array}$ & $\begin{array}{l}\text { Demonstração do } \\
\text { fluxo de caixa }\end{array}$ \\
\hline Saída & RES & Superávit/Déficit & $\begin{array}{l}\text { Verificar o } \\
\text { resultado gerado } \\
\text { no período }\end{array}$ & $\begin{array}{l}\text { Demonstração do } \\
\text { resultado para o } \\
\text { superávit/ } \\
\text { déficit }\end{array}$ \\
\hline
\end{tabular}

Fonte: elaboração própria.

A tabulação dos dados foi levada a cabo em uma planilha Excel ${ }^{\circledR}$ para em seguida se proceder ao agrupamento necessário à formulação explicitada no quadro 4. Ressalta-se que na variável INVAI levou-se em conta o valor total contabilizado como ativo intangível - atleta profissional apresentado no balanço patrimonial de cada clube.

O acesso aos dados para este estudo se deu pela pesquisa das demonstrações contábeis divulgadas por meio eletrônico dos clubes selecionados. Tais peças, em geral, acham-se no site do próprio clube, no site da federação estadual de futebol a qual a organização está vinculada ou são disponibilizadas nos diários oficiais dos estados.

Quanto à análise dos dados, inicialmente foi realizada uma estatística descritiva verificando média, variância e desvio padrão de todos os dados coletados, a fim de conhecer os traços da amostra estudada e a magnitude das variáveis estudadas.

Por fim, para o alcance do objetivo principal da pesquisa, de identificar o nível de eficiência da gestão dos clubes brasileiros no aproveitamento do recurso atleta, foi utilizada a análise envoltória de dados, a qual foi trabalhada através do software $\operatorname{SIAD}^{\circledR}$ v.3. Este programa tem sido utilizado em várias pesquisas, apresentando a vantagem de ser um programa gratuito e também aceitar um número superior de unidades produtivas em relação aos demais programas (DANTAS; BOENTE, 2011, 2012; DANTAS, 2013; SOUZA, 2014).

As unidades de decisão, utilizadas neste estudo, foram os clubes exibidos no quadro 3. Obedeceu-se ao critério de Fitzsimmons e Fitzsimmons (2000) para definir a quantidade de unidades a serem analisadas. 
Considerando a realidade do trabalho que se quis fazer, a alternativa DEA que melhor se aplicou foi a VRS, visto que esta alternativa não assume a existência de proporcionalidade entre as entradas e saídas, o que permite comparar DMU's de portes distintos (SILVEIRA, MEZA, MELLO, 2011). A DEA foi orientada à saída visto que o objetivo era maximizar a saída com os recursos existentes (PEDROSA, 2014).

Dentro do espaço temporal escolhido (2010 a 2013) foi analisada a eficiência de cada clube em alcançar receitas, fluxo de caixa e resultados (superávit ou déficit) decorrentes do investimento em atletas conforme apresentadas no quadro 5.

Quadro 5 - Relações adotadas para análise da eficiência dos clubes

\begin{tabular}{|l|l|l|}
\hline \multicolumn{1}{|c|}{ Função } & \multicolumn{1}{|c|}{ Relação } & \multicolumn{1}{c|}{ Objetivo } \\
\hline $\mathrm{C}(\mathrm{x})=(y 1, y 2, y 3)$ & INVAI $\rightarrow$ REC, FCX, RES & $\begin{array}{l}\text { Analisar a eficiência do clube em gerar todos os } \\
\text { benefícios econômicos }\end{array}$ \\
\hline $\mathrm{C}(x)=\left(y_{1}\right)$ & INVAI $\rightarrow \mathrm{REC}$ & $\begin{array}{l}\text { Analisar a eficiência do clube em gerar receitas através } \\
\text { do investimento em atleta }\end{array}$ \\
\hline $\mathrm{C}(x)=\left(y_{2}\right)$ & INVAI $\rightarrow \mathrm{FCX}$ & $\begin{array}{l}\text { Analisar a eficiência do clube em gerar fluxo de caixa } \\
\text { através do investimento em atletas }\end{array}$ \\
\hline $\mathrm{C}(x)=\left(y_{3}\right)$ & INVAI RES & $\begin{array}{l}\text { Analisar a eficiência do clube em obter resultados } \\
\text { (superávit ou déficit) através do investimento em atletas }\end{array}$ \\
\hline
\end{tabular}

Fonte: elaboração própria.

Com esta tática, foi possível verificar o desempenho anual dos clubes identificando qual o escopo de eficiência dos mesmos nos parâmetros da DEA, bem como em qual benefício econômico cada clube possui melhor desempenho. O que será abordado na seção seguinte.

\section{Resultados}

A presente seção objetiva descrever, analisar e interpretar os dados coletados, dividindose em duas subseções: a primeira que trata da análise descritiva dos dados e a segunda aborda a análise envoltória de dados, a fim de averiguar a performance dos clubes.

\subsection{Estatística Descritiva}

Confirmando o que já está consolidado na sociedade, ou seja, que os clubes estão dispostos a investir quantias exorbitantes na aquisição de atletas, verificou-se que as organizações da amostra estudada investiram em média $\mathrm{R} \$ 6.169 .667,27$ no quadro de jogadores nos anos analisados (2010 a 2013). O ano de 2012 apresentou um pico no investimento em atletas (INVAI), chegando a uma média de R\$18.001.034,32.

Por outro lado, o ano de 2013 revelou o menor valor para esta variável no período (redução de R\$ 4.515.956,95). Isso ocorreu pelo fato de muitos clubes exibirem redução nos seus quadros ou valores expressivos na amortização do valor dos seus atletas. O gráfico 1 destaca os valores médios por clube, para esta variável no período analisado.

Em sequência uma das formas de visualizar o retorno financeiro era analisando as receitas auferidas no período, a qual é representada neste estudo pela variável REC. No caso específico dos clubes de futebol, para o presente trabalho, utilizaram-se as receitas com bilheteria, transmissão de jogos, patrocínio, venda de produtos com a marca do clube, premiações de campeonatos e com sócio-torcedor, visto que estudos anteriores apontaram o investimento em atletas (INVAI) como responsável por captar esses tipos de receitas.

No período analisado (2010 a 2013), os clubes demonstraram, em média, receitas de $\mathrm{R} \$$ 74.874.782,69, sendo os clubes Corinthians, Flamengo, São Paulo, Santos e Palmeiras, os que 
alcançaram os maiores patamares de entradas de recursos sob a forma de receitas, todos com uma média no período acima dos 100 milhões de reais.

Gráfico 1 - Valor médio do investimento em atletas por clube no período em análise (Em milhares de reais)

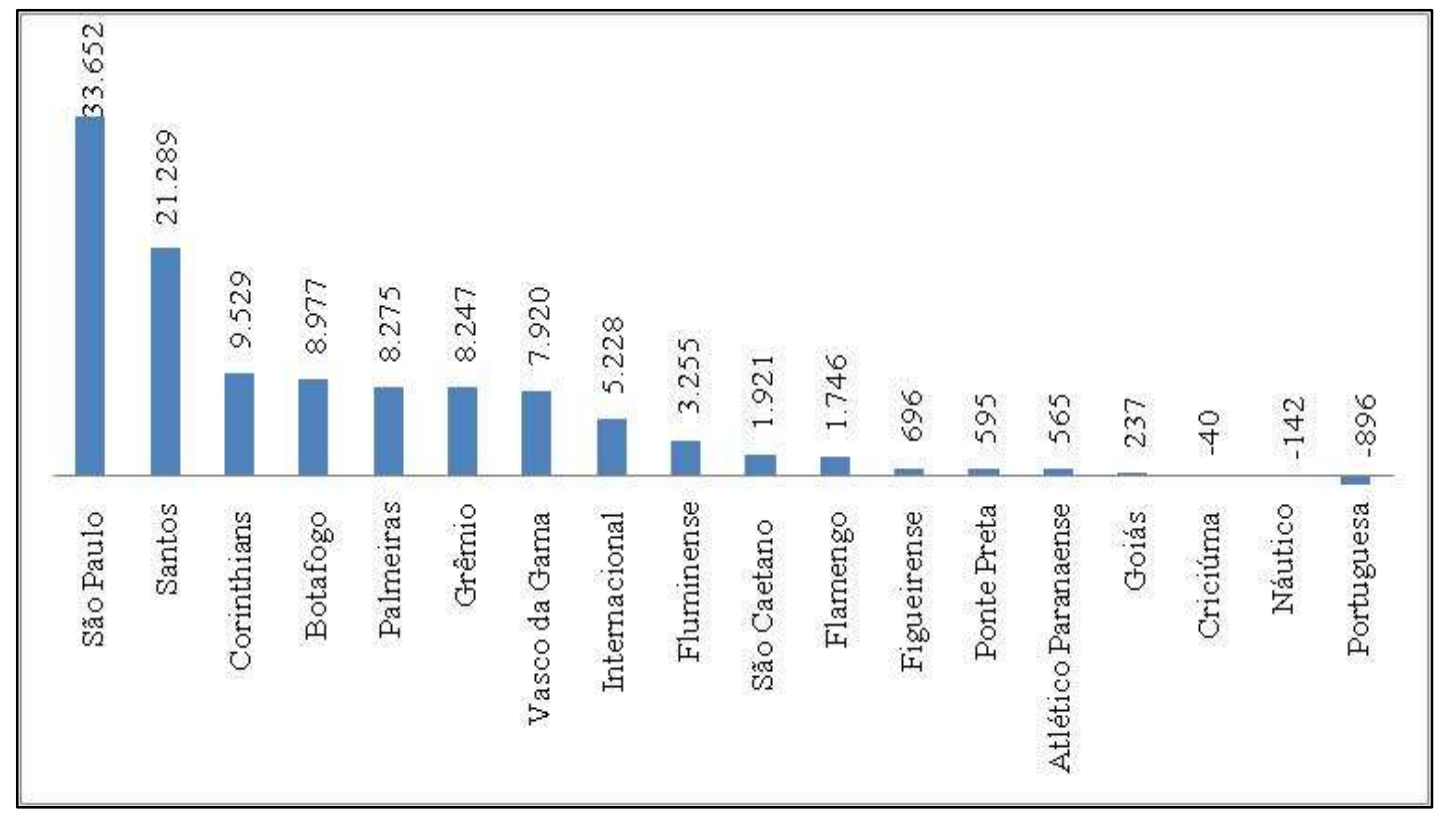

Fonte: Dados da Pesquisa.

O outro benefício que a literatura aponta como relacionado ao investimento em atletas é o fluxo de caixa gerado (FCX). Observou-se que os clubes da amostra delineada apontaram uma pluralidade de valores gerados no caixa, apresentando uma média de $\mathrm{R} \$ 4.557 .781,05$ no período analisado.

Por último, os resultados (superávit/déficit) também são considerados benefícios que podem ser gerados a partir do investimento em atletas. No entanto, os clubes de futebol brasileiro têm amargado valores negativos neste aspecto. De fato, no período analisado, as organizações da amostra retrataram um déficit médio de $\mathrm{R} \$ 10.255 .309,82$.

No que se refere ao valor médio do resultado apresentado pelos clubes no período analisado, entre 2010 e 2013, o ano de 2012 foi o que apresentou um resultado menos dramático, fechando com um superávit médio de R $\$ 4.095 .090,51$. Ressalta-se que apenas o Corinthians e o São Paulo tiveram superávit em todos os anos analisados.

Dessa forma, através da análise descritiva foi possível concluir e confirmar os altos investimentos que os clubes estão dispostos a realizar no seu quadro de atletas, ao mesmo tempo que se ratificou que estes conseguem gerar receitas bilionárias. Por outro lado, a geração de caixa não exibiu os mesmos patamares, o que revelou certa dificuldade que estas organizações apresentaram em saldar suas dívidas. Outro contrassenso mostrou-se na geração de resultados por parte dos clubes, já que os mesmos apesar de contabilizarem altas receitas, findam os exercícios fiscais com déficits que se arrastam por anos. Destaca-se ainda que em 2013 houve uma queda no valor da variável INVAI. Isso se deu pelo fato de alguns clubes terem diminuído o seu quadro de jogadores, bem como em outros casos houve a redução do valor dos mesmos.

O gráfico 2 resume os dados médios, expressos em milhares de reais, por ano analisado, das variáveis estudadas na presente pesquisa.

Em seguida, realizou-se a análise de envoltória com o objetivo de verificar a eficiência dos clubes em alcançar benefícios econômicos através do investimento realizado em atletas. 


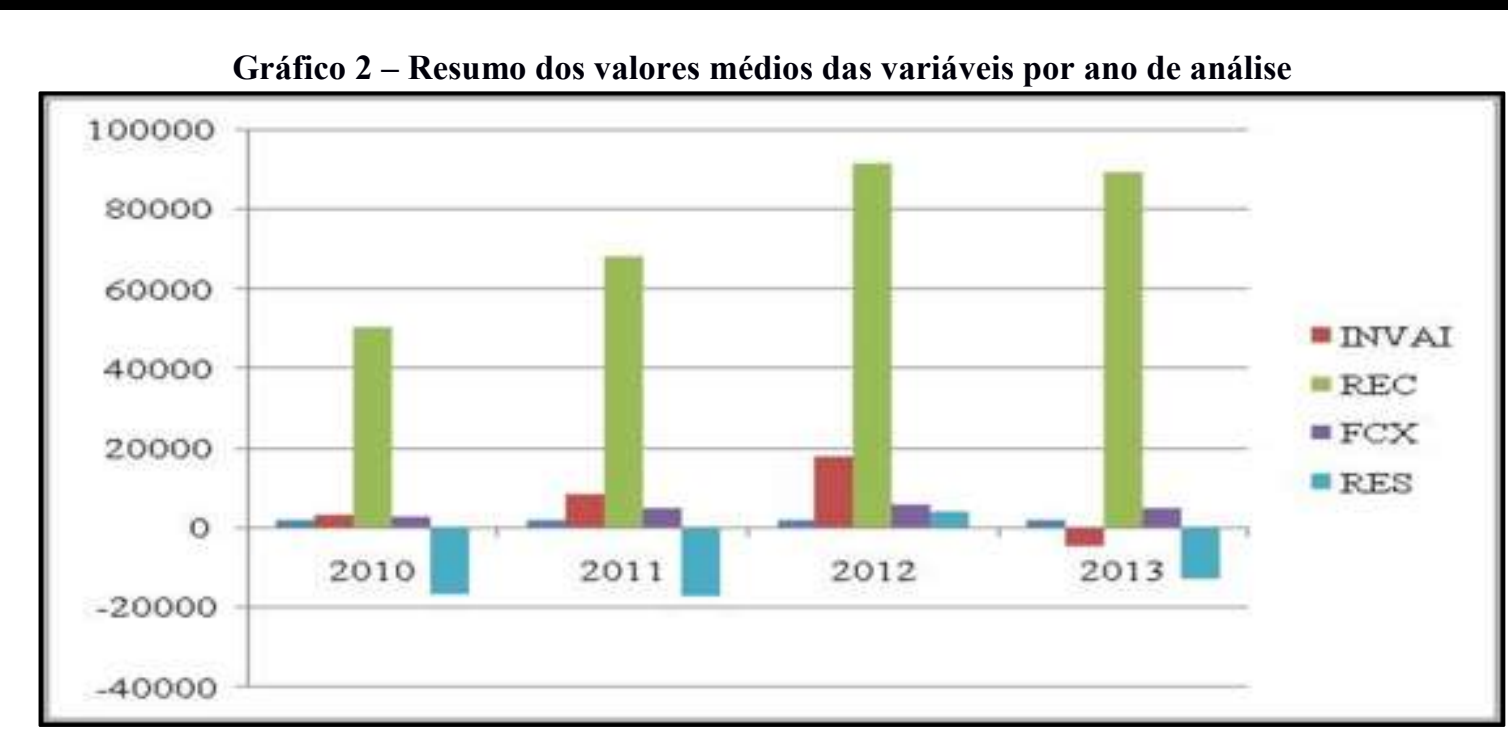

Fonte: Dados da Pesquisa.

\subsection{Análise Envoltória de Dados}

Através da análise envoltória de dados, foram formulados indicadores de desempenho para os clubes de futebol que compuseram a amostra do estudo. Verificou-se conforme apontado no gráfico 3 que o ano de 2011, foi o ano que revelou melhor desempenho na geração global dos benefícios econômicos, sendo ainda os valores anuais muito distantes do considerado ideal.

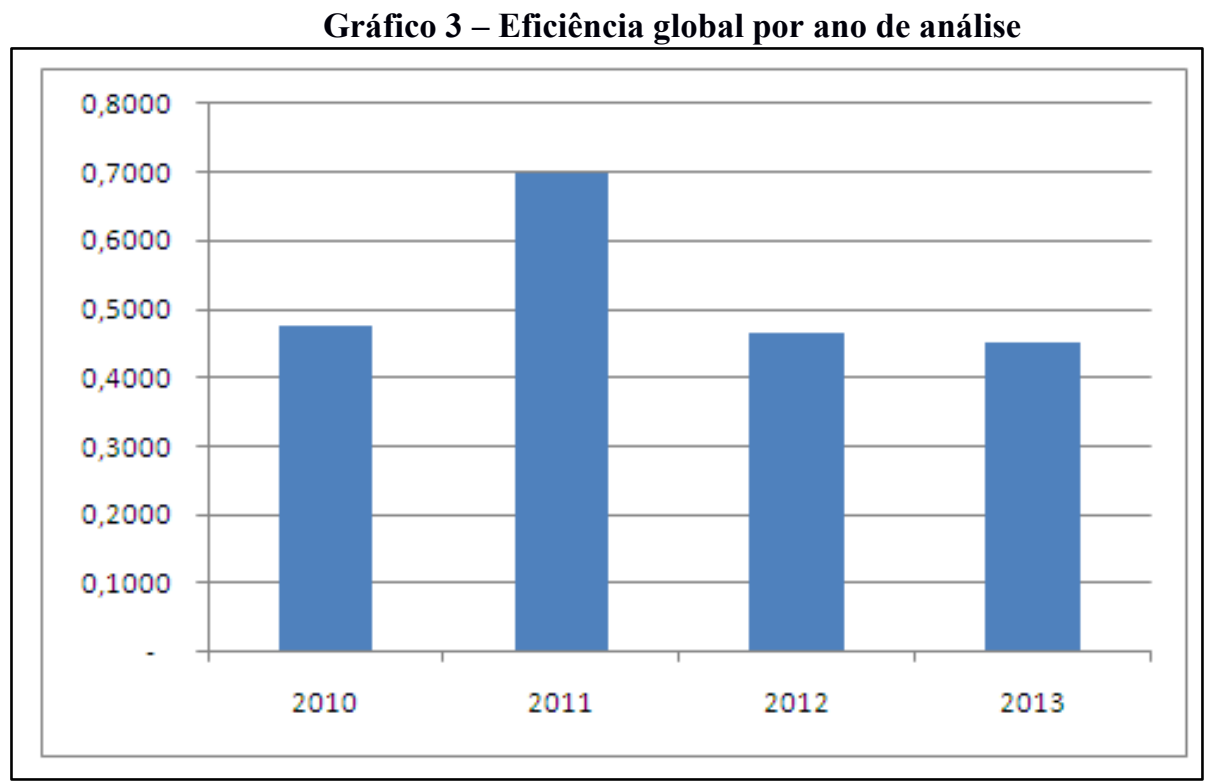

Fonte: Dados da Pesquisa.

Averiguou-se ainda que dos três benefícios econômicos analisados, a variável REC foi aquela que os clubes tiveram melhor desempenho, por outro lado, a variável RES, que exibe o superávit ou déficit da organização, foi a com mais baixo indicador de eficiência, denotando assim a dificuldade por parte dos clubes em alcançar bons resultados neste quesito, conforme apontado no gráfico 4. No entanto, esse resultado era de se esperar, visto que como já abordado anteriormente, os clubes de futebol brasileiros apresentam dificuldades em gerar superávit. 
Gráfico 4 - Eficiência anual para cada variável selecionada pelo estudo

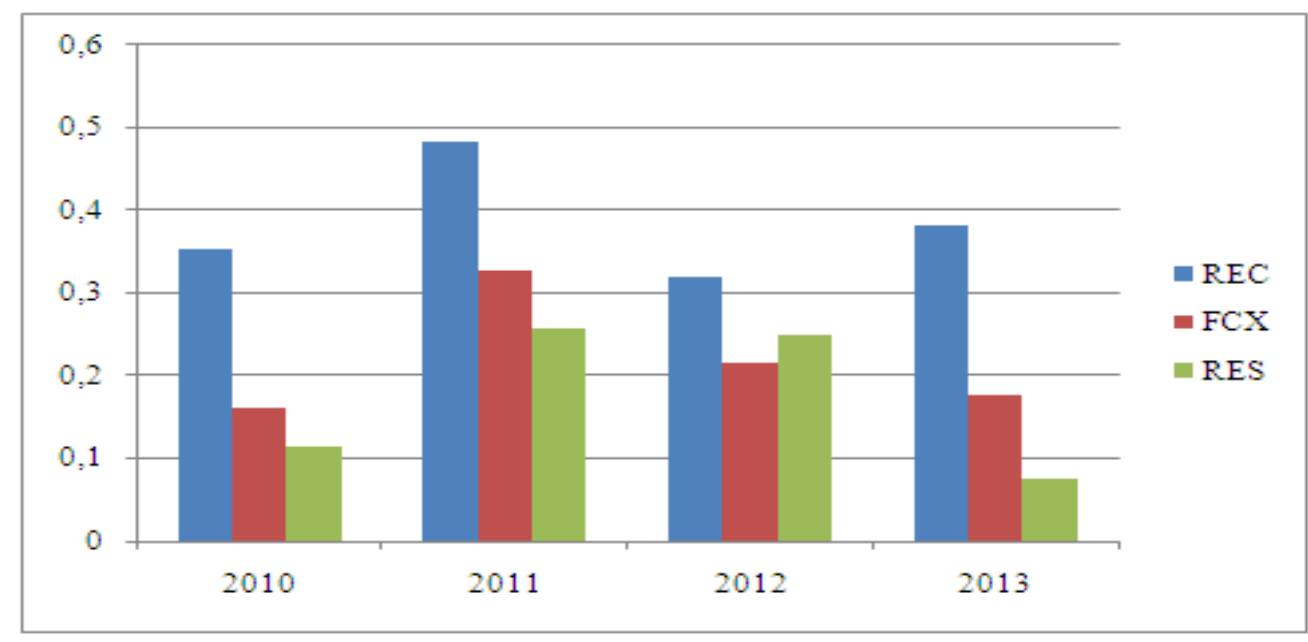

Fonte: Dados da Pesquisa.

A seguir será listado, de forma mais acurada, a análise de eficiência dos clubes por ano estudado em termos da DEA.

\subsubsection{Análise Envoltória de Dados para o Ano de 2010}

Inicialmente, foi calculado o índice de eficiência global dos clubes, ou seja, o grau de desempenho em gerar todos os benefícios econômicos através do investimento realizado em atletas. Averiguou-se que neste aspecto inicial, os clubes Atlético Paranaense, Corinthians e Internacional apresentaram o grau de eficiência máxima (1) no ano de 2010.

No entanto, para verificar qual desses clubes apresentou o melhor desempenho, faz-se necessário analisar o indicador de eficiência fornecido pela fronteira invertida. Giacomello e Oliveira (2014) destacaram que no caso específico da fronteira invertida, quanto menor for o valor do índice, melhor é o comportamento do componente da amostra. Diante disso, conforme apontado na tabela 1 , temos que o Corinthians foi o mais eficiente.

Tabela 1 - Clubes eficientes em 2011

\begin{tabular}{l|r|r}
\hline \multicolumn{1}{c|}{ DMU } & Padrão & Invertida \\
\hline Corinthians & 1,0000 & 0,0288 \\
\hline Atlético Paranaense & 1,0000 & 0,1647 \\
\hline Internacional & 1,0000 & 1,0000 \\
\hline
\end{tabular}

Fonte: Dados da Pesquisa.

Verificou-se que a eficiência dos clubes está bem abaixo do considerado ideal, sendo a média do indicador de desempenho 0,457 . O gráfico 5 elenca os clubes e seus indicadores para o ano de 2010.

Sabe-se que os três clubes já citados apresentaram eficiência na geração de benefícios. No entanto, torna-se necessário averiguar em qual benefício cada clube apresenta melhor desempenho. Para isso foi calculada, a eficiência individual dos clubes em gerar cada um dos benefícios.

No que tange aos clubes que foram considerados eficientes tem-se que:

a) O clube considerado eficiente na geração de receitas foi o Corinthians;

b) Na geração de caixa, o clube considerado eficiente foi o Internacional;

c) No que tange à geração de superávit, foram eficientes o Atlético Paranaense e o 
Corinthians.

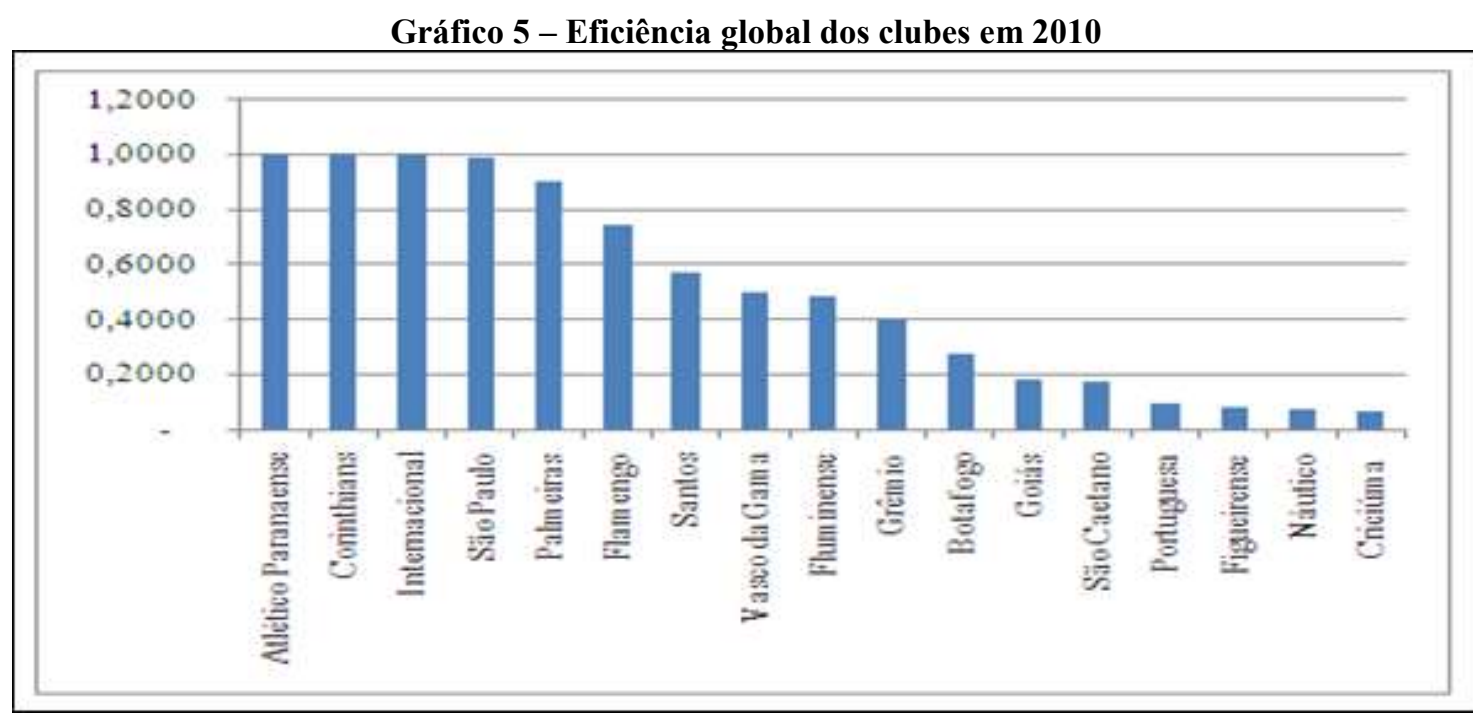

Fonte: Dados da Pesquisa.

Ressalta-se que, em 2010, o Corinthians mesmo apresentando diminuição do seu ativo intangível (redução de R\$ 1.364.000,00) foi considerado eficiente na geração de dois tipos de benefícios econômicos. Resultado semelhante foi obtido pelo Internacional, eficiente na geração de caixa, mesmo reduzindo em $\mathrm{R} \$ 602.360,00$ o seu ativo intangível. Compreende-se, através destes resultados que para um clube alcançar os resultados financeiros satisfatórios, não precisa apenas investir mais em recursos estratégicos: necessita saber utilizar adequadamente os recursos que estão disponíveis, tal como ocorreu com o Corinthians e Internacional. O gráfico 6 destaca a eficiência dos dezoito clubes analisados na geração de cada um dos benefícios econômicos.

Gráfico 6 - Eficiência dos clubes na geração de benefícios econômicos em 2010 na amostra selecionada

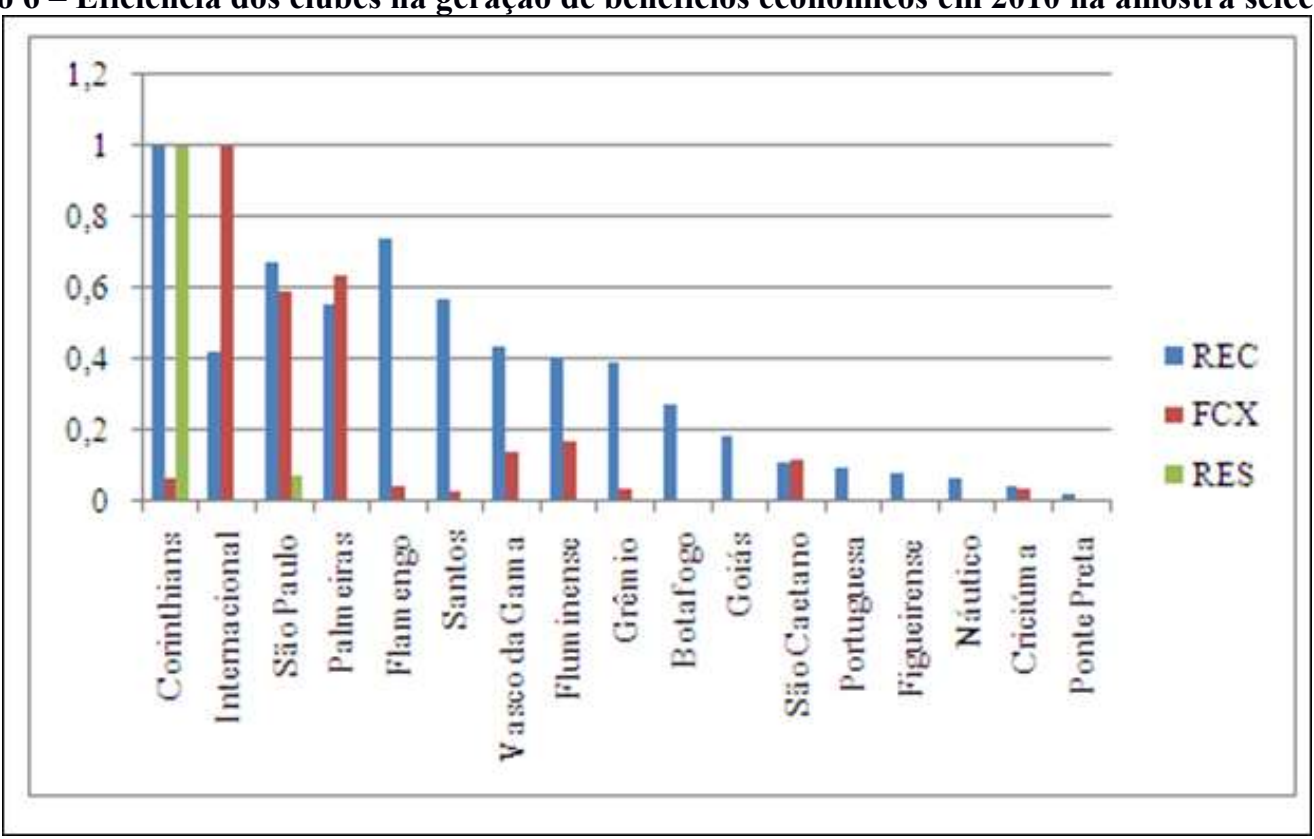

Fonte: Dados da Pesquisa.

Em seguida, procedeu-se à análise de eficiência dos clubes no ano de 2011, conforme 
apontado a seguir.

\subsubsection{Análise Envoltória de dados para o Ano de 2011}

O ano de 2011 ostentou cinco clubes como eficientes. No entanto, verificou-se que Santos e Criciúma foram os que apresentaram melhor desempenho dentro do grupo de clubes eficientes através da análise da fronteira invertida, conforme aponta a tabela 2.

Tabela 2 - Clubes eficientes em 2011

\begin{tabular}{c|c|c|}
\hline \multicolumn{3}{c}{ Tabela 2 } \\
\hline Clubes & Padrão & Invertida \\
\hline Santos & 1 & 0,240123 \\
\hline Criciúma & 1 & 0,5242 \\
\hline Atlético Paranaense & 1 & 1 \\
\hline Botafogo & 1 & 1 \\
\hline Corinthians & 1 & 1 \\
\hline Palmeiras & 1 & 1 \\
\hline Ponte Preta & 1 & 1 \\
\hline Internacional & 1 & 1 \\
\hline São Paulo & 1 & 1 \\
\hline \multicolumn{3}{|c|}{ Fonte: Dados da Pesquisa. }
\end{tabular}

O gráfico 7 ainda aponta que, no que tange à eficiência global, o Goiás foi o menos eficiente (indicador de 0,131). A média para o desempenho dos clubes neste ano foi de 0,6979.

Gráfico 7 - Eficiência global dos clubes em 2011

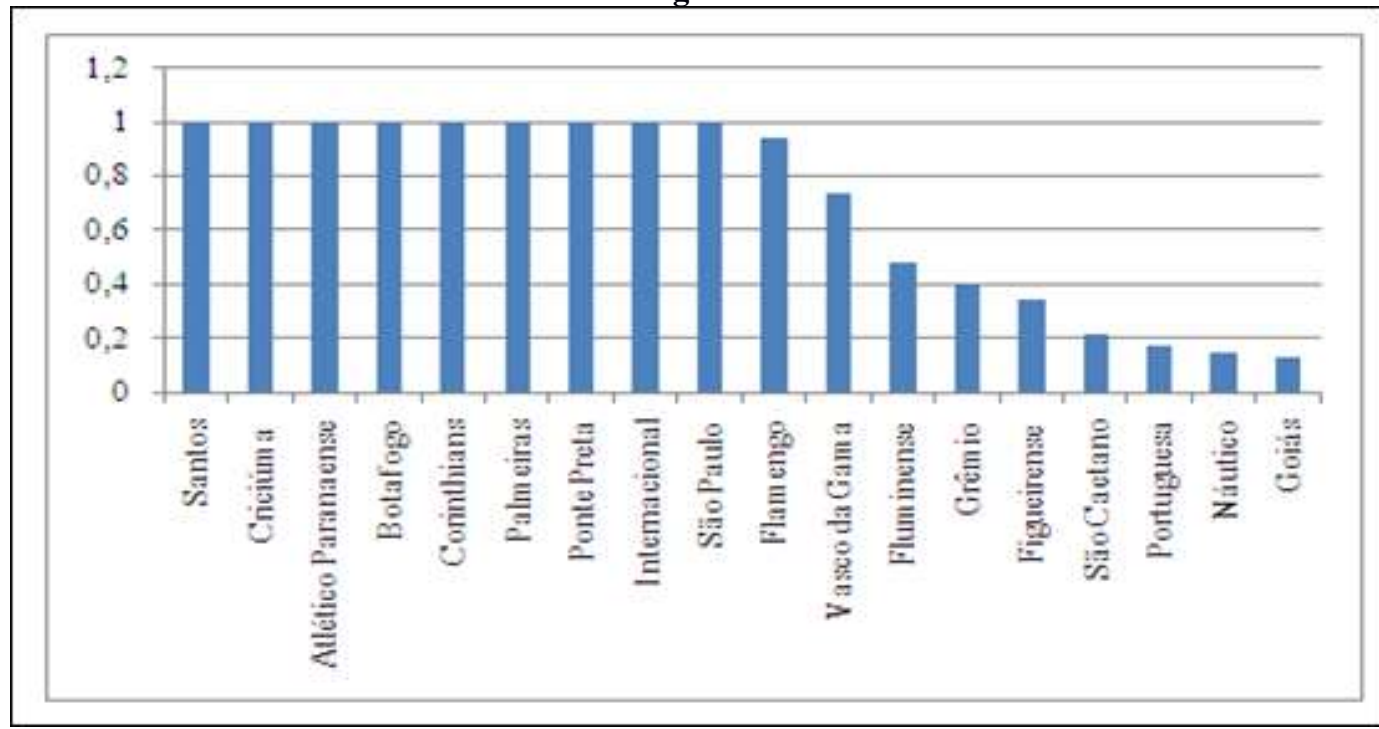

Fonte: Dados da Pesquisa.

Constatou-se que, no que se refere à eficiência no alcance de cada benefício de forma individual, Corinthians, Palmeiras, Santos e São Paulo foram eficientes na geração de receitas. O Palmeiras, em que pese sua redução no ativo intangível (menos $\mathrm{R} \$$ 9.468.000,00), apresentou-se como eficiente tanto para a geração de receitas como para a geração de caixa. No caso da segunda variável, clubes como Atlético Paranaense, Internacional e São Paulo também apresentaram bom desempenho. 
Na geração de lucro foram considerados eficientes o Corinthians, Criciúma, Santos e São Paulo. O gráfico 8 sumariza os resultados da eficiência por variável de cada clube analisado.

Gráfico 8 - Eficiência dos clubes na geração de benefícios econômicos em 2011 na amostra selecionada

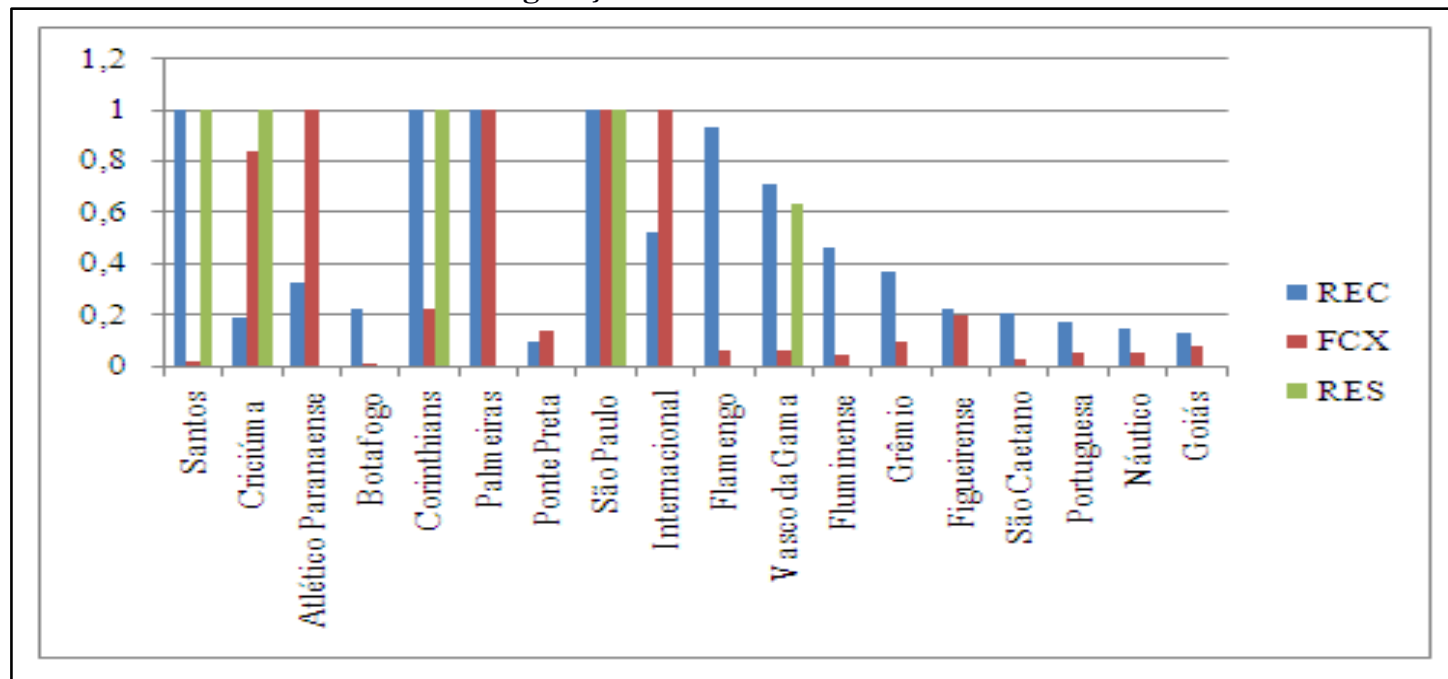

Fonte: Dados da Pesquisa.

Mais uma vez, agora no ano de 2011, foi constatado que um clube, o Palmeiras, que não investiu em atletas, em verdade reduziu seu ativo intangível, pôde ser considerado eficiente na geração de benefícios econômicos, tal como aconteceu em 2010 com o Corinthians.

\subsubsection{Análise Envoltória de Dados para o Ano de 2012}

Em 2012 constatou-se três clubes eficientes: Atlético Paranaense, Corinthians e Grêmio. No entanto, o Corinthians apresentou o melhor desempenho, conforme destacado na tabela 3 que evidencia os resultados da fronteira invertida.

Tabela 3 - Clubes eficientes em 2012

\begin{tabular}{c|r|r|}
\hline Clube & \multicolumn{1}{c|}{ Padrão } & Invertida \\
\hline Atlético Paranaense & 1,000 & 0,406 \\
\hline Corinthians & 1,000 & 0,064 \\
\hline Grêmio & 1,000 & 0,195 \\
\hline
\end{tabular}

Fonte: Dados da Pesquisa.

A média de eficiência para o ano de 2012 foi de 0,463 , o que denota uma redução no desempenho dos clubes entre 2011 e 2012. A Ponte Preta foi o clube menos eficiente no período analisado, conforme apontado no gráfico 9.

Individualmente, exibiu-se que o Corinthians foi o mais eficiente na geração de receitas e caixa no período analisado. Já para a geração de resultados, citam-se Atlético Paranaense, Grêmio e São Paulo como eficientes. Ressalte-se que o São Paulo foi eficiente na geração de resultados, mas não apresentou bom desempenho global; no entanto, chegou próximo desse resultado, pois teve indicador de eficiência global 0,890 .

Informa-se que o Corinthians e o Grêmio, que foram considerados eficientes no período, apresentaram no mesmo ano redução dos seus ativos intangíveis (o Corinthians apresentou redução de $\mathrm{R}$ \$ 3.822.000,00 e o Grêmio de $\mathrm{R}$ \$ 8.386.000,00). Estes dados ratificam ainda ainda 
mais o fato de que para ser eficiente não é necessário investir mais, mas gerenciar e utilizar bem os recursos disponíveis.

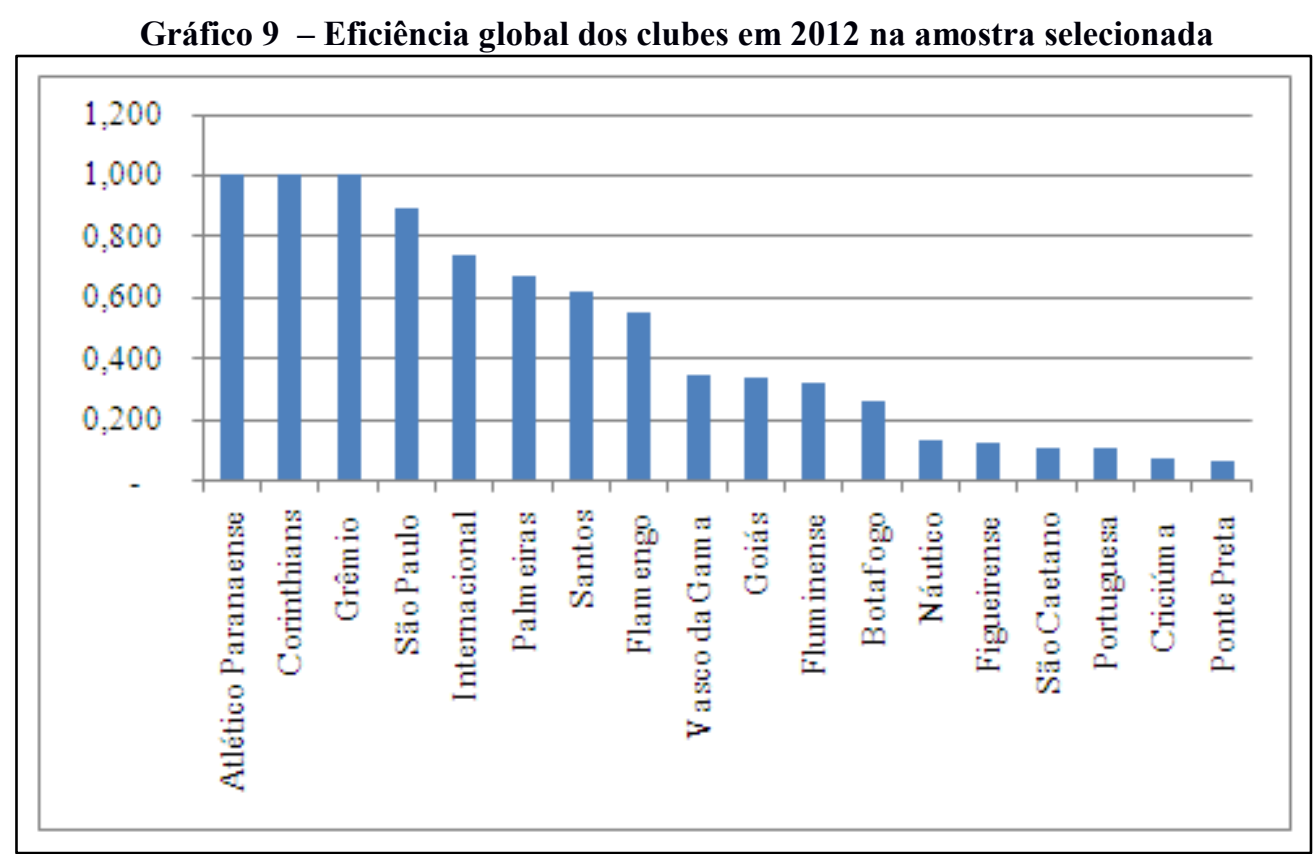

Fonte: Dados da Pesquisa.

No gráfico 10 são evidenciados os clubes estudados e seus índices de eficiência em cada variável analisada.

Gráfico 10 - Eficiência dos clubes na geração de benefícios econômicos em 2012 na amostra selecionada

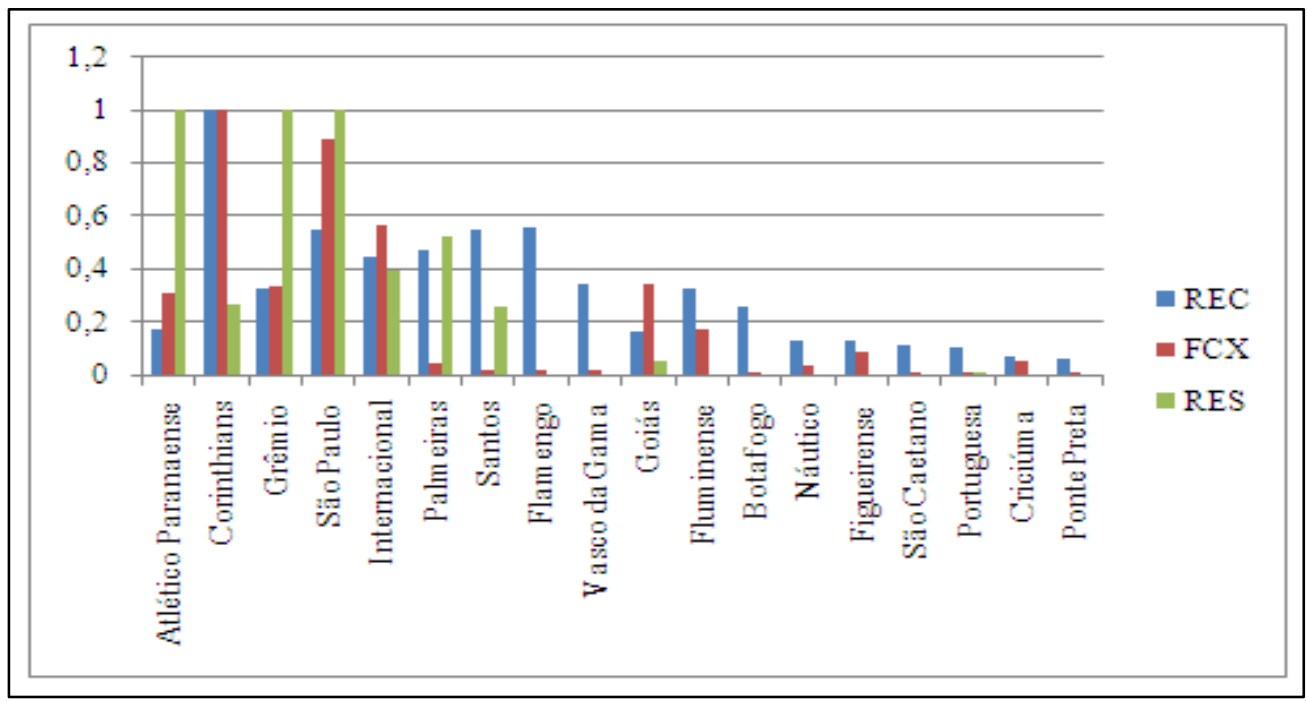

Fonte: Dados da Pesquisa.

\subsubsection{Análise Envoltória de Dados para o Ano de 2013}

Verificou-se que no ano de 2013, os clubes considerados eficientes em gerar o conjunto de benefícios econômicos foram o Flamengo, Fluminense e o São Paulo. Através da análise da fronteira invertida, verificou-se que dos três clubes considerados eficientes, o que exibiu melhor desempenho foi o Flamengo. O gráfico 11, apresenta o ranqueamento dos clubes para o ano de 
2013.

Gráfico 11 - Eficiência global dos clubes em 2013 na amostra selecionada

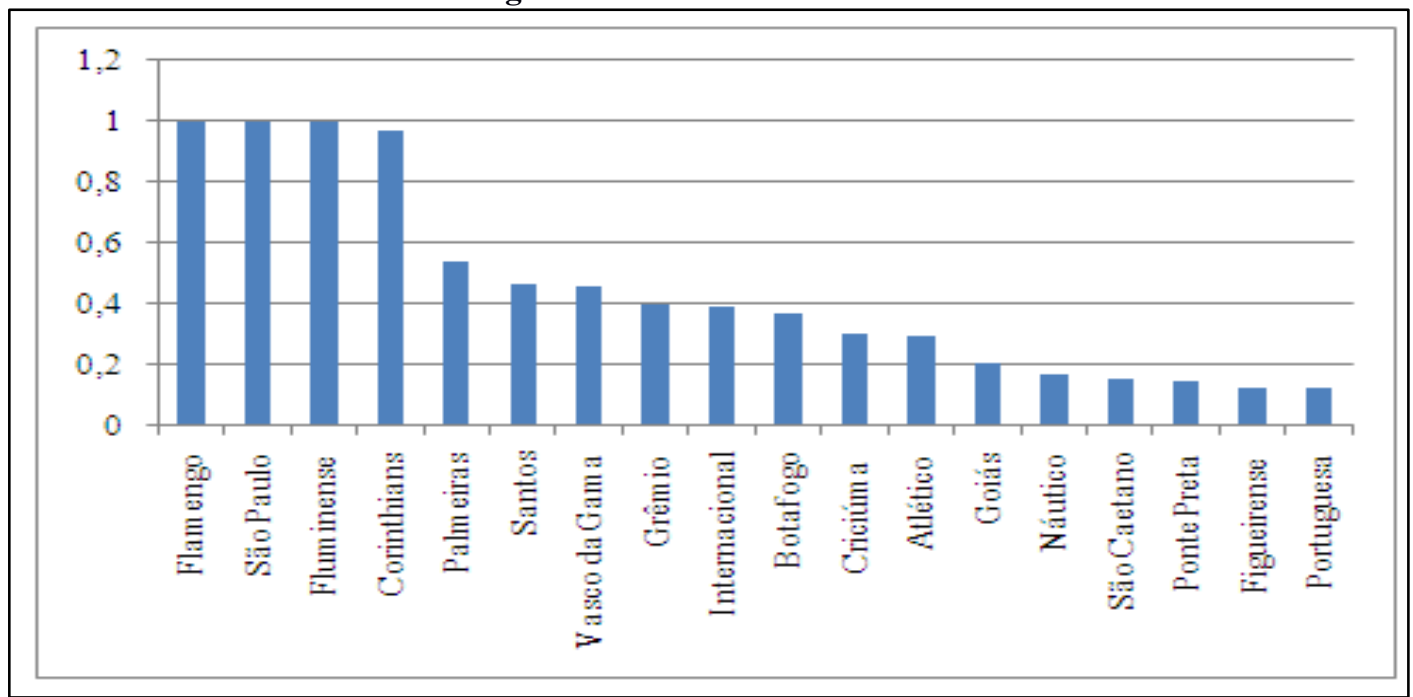

Fonte: Dados da Pesquisa.

No entanto, é necessário verificar em quais variáveis os clubes são mais eficientes, pois assim será possível identificar para onde os esforços organizacionais estão sendo mais direcionados. Através da análise envoltória por variável afloram os seguintes resultados:

a) O Flamengo apresentou eficiência na geração de receitas, mas não obteve o mesmo desempenho no alcance de caixa e superávit;

b) O Fluminense foi eficiente na geração de caixa, sendo, todavia, ineficiente na geração de receita e superávit;

c) O São Paulo foi considerado eficiente na geração de resultado (superávit); no entanto, não apresentou bom desempenho na geração de caixa e de resultado.

Diante desses resultados, evidencia-se que, no ano de 2013, apesar de três clubes terem sido considerados eficientes cada um apresentou melhor desempenho no alcance de um dos objetivos econômicos. Especula-se aparentemente, que os esforços da administração dessas organizações estão concentrados em obter retornos específicos em um dos tipos de benefício econômico.

Torna-se ainda necessário destacar que, todos os três clubes considerados eficientes, contabilizaram redução dos seus ativos intangíveis no ano de 2013. O gráfico 12, mostra o resumo dos indicadores de eficiência dos clubes por variável. Ressalta-se que, de maneira geral, os 18 clubes estudados apresentam um desempenho melhor na geração de receitas (média de eficiência 0,382), se comparados com os demais benefícios (média de eficiência na geração de caixa de 0,176 e geração de lucro 0,076), no ano de 2013.

Concluindo esta seção do estudo compila-se que o Corinthians se apresentou como eficiente em praticamente todo período estudado, revelando uma pequena redução no desempenho em 2013, quando alcançou um indicador de desempenho de 0,965.

O clube ainda pôde ser considerado referência na geração de receitas, visto que nos anos de 2010 a 2012 figurou entre as organizações mais eficientes na captação da variável citada, e mesmo no ano de 2013, quando apresentou queda no desempenho, obteve um índice de 0,948 , ou seja, muito próximo da eficiência máxima. 
Gráfico 12 - Eficiência dos clubes na geração de benefícios econômicos em 2013 na amostra selecionada

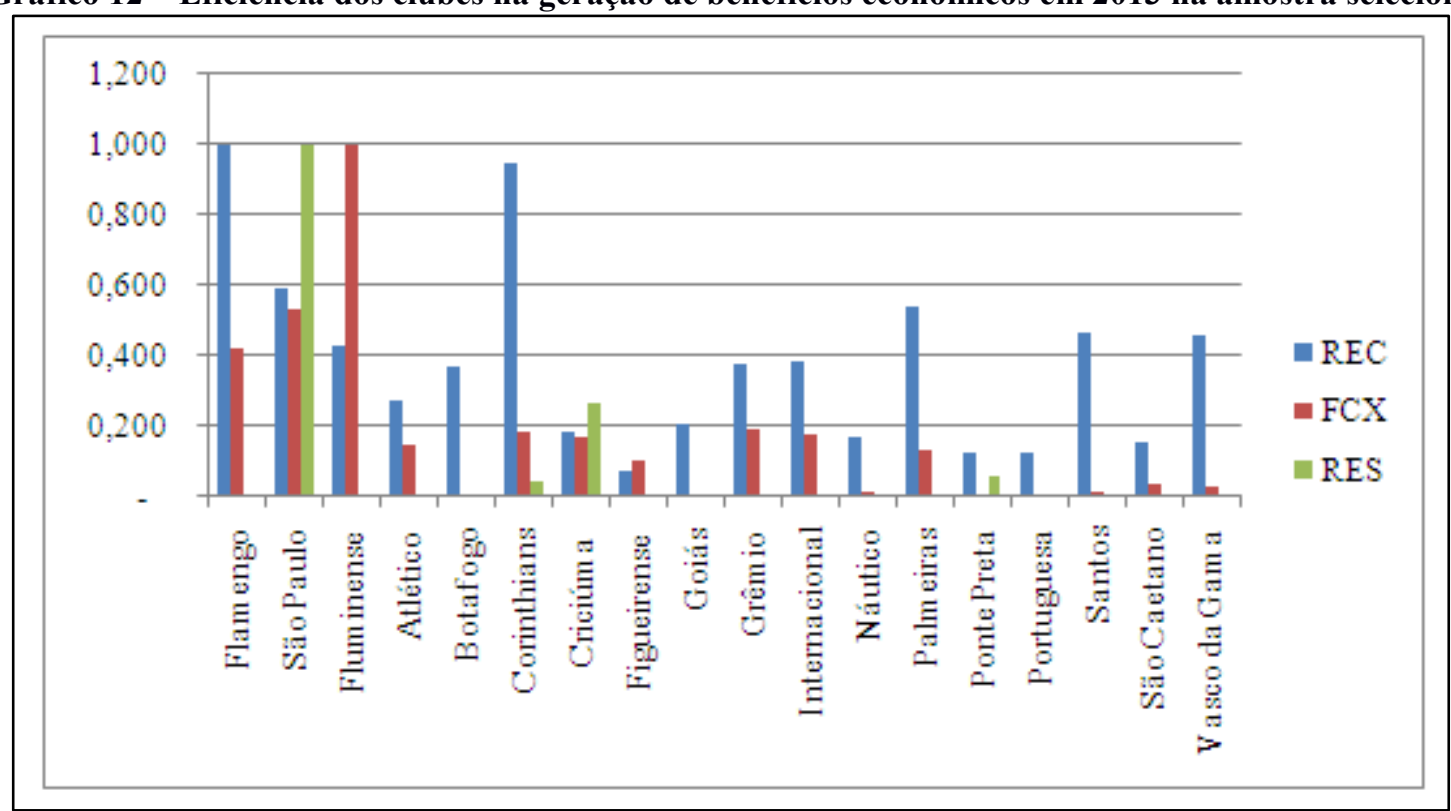

Fonte: Dados da Pesquisa.

Destaca-se também o fato de que em todos os anos analisados, ao menos um clube considerado eficiente apresentou redução do seu ativo intangível, o que reforça o fato de que o essencial é saber fazer uso dos recursos disponíveis para o alcance da eficiência. Com isso o estudo apontou que as organizações esportivas estudadas ainda não utilizam todo o potencial dos seus atletas, tendo em vista que estes podem ser considerados recursos estratégicos à luz da RBV, ao mesmo tempo que ficou aberta a discussão sobre ser coerente a contabilização dos atletas como ativos intangíveis, já que os clubes não conseguem atingir com eficiência a geração de receitas, de caixa e lucro, os quais são benefícios econômicos esperados, com o valor do investimento em atletas, apesar dos mesmos destacarem altos valores nessa conta contábil.

Esse resultado confirma os achados de Risalti e Verona (2013), quando esses autores constataram que o investimento em atletas nem sempre está associado à geração de receitas por parte dos clubes de futebol no contexto italiano. Com a base traçada pelo presente estudo é possível identificar a possibilidade de esta ser uma realidade também no contexto brasileiro. Assim, chega-se ao entendimento que outras variáveis podem proporcionar um melhor desempenho dos clubes no aspecto financeiro, tal como apontado nos estudos de Pereira et al. (2015), Nascimento et al. (2015) e Dantas, Machado e Macedo (2015).

\section{Conclusão}

O objetivo deste trabalho foi verificar o desempenho dos clubes de futebol brasileiro na utilização do atleta como ativo intangível e recurso estratégico para a geração de benefícios econômicos entre os períodos de 2010 a 2013.

O contexto em que esta pesquisa está inserida destaca a necessidade dos clubes obterem retorno econômico oriundo do investimento em atletas, não apenas por conta da magnitude das aplicações, mas também pela característica de ativo intangível e recurso estratégico atribuída aos jogadores, tal como sugere a Visão Baseada em Recursos.

Através da análise descritiva dos dados constatou-se que os valores financeiros dos clubes atingem patamares milionários. Entre os anos de 2010 a 2013 houve um investimento médio de $\mathrm{R} \$ 18.001 .034,32$ em atletas, ao mesmo tempo que houve uma geração de $\mathrm{R} \$$ 
74.874.782,69 em receitas e $\mathrm{R} \$ 4.557 .781,05$ em fluxo de caixa. Laconicamente, entretanto, os resultados dos clubes continuam negativos no que se refere à geração de superávit, vez que no período analisado a média foi um déficit de $\mathrm{R} \$ 10.255 .309,82$, obtendo resultados positivos em todos os anos investigados apenas pelo Corinthians e pelo São Paulo.

Por outro lado, no que tange à eficiência, constatou-se, através da análise envoltória de dados, problemas por parte dos clubes, visto que os índices anuais de desempenho ficaram bem abaixo do que é considerado eficiente. (O ano de 2011 denotou o melhor desempenho médio para a eficiência global $(0,7))$.

Verificou-se também que as receitas compõem a variável cujo alcance pelos clubes têm melhor desempenho; em paralelo a variável resultado (superávit ou déficit) contabilizaram certa dificuldade de realização por parte das organizações esportivas.

Ressalta-se que em todos os anos analisados, clubes que não apresentaram investimento em seus ativos intangíveis foram considerados eficientes, o que reforça a ideia de que para ser eficiente não é necessário evidenciar mais investimentos em recursos, mas o melhor aproveitamento daqueles que estão disponíveis, ao mesmo tempo que, torna discutível o tratamento dos atletas como ativos intangíveis, pois, ao que parece, esses não são os principais responsáveis pela geração de benefícios econômicos nas organizações esportivas. Tal entendimento pode enfraquecer, inclusive, a compreensão do atleta como um recurso estratégico à luz da Visão Baseada em Recursos.

Quanto às limitações da pesquisa temos a pequena quantidade de clubes estudados. A principal causa para esta limitação deu-se pelo fato da ausência de divulgação de informações contábeis por parte dos clubes de futebol brasileiros, cujo quesito transparência ainda deixa muito a desejar.

Por tratar-se de estudo quantitativo, a inserção de outros fatores como a expertise dos gerentes, contexto social de vivência do clube, sistemas de controle interno, entre outros, que podem ser relevantes para a verificação da performance organizacional, configuram-se como limitantes do atual relato, conforme o mesmo foi desenhado. Todavia, seus resultados podem fornecer indícios da necessidade de um melhor gerenciamento dos recursos estratégicos, em uma área onde existem investimentos milionários, a fim de que os retornos sejam alcançados com a máxima eficiência.

Em adição, a fim de ampliar o estudo do tema abordado nesse trabalho, apresentamse algumas sugestões para futuras pesquisas, além da ampliação do período deste estudo, a saber: Comparação entre o desempenho dos clubes brasileiros com a performance apresentada por clubes internacionais; uma outra abordagem de pesquisa, que pode ampliar o presente estudo, diz respeito à verificação de quais variáveis tornam o clube eficiente em gerar benefícios econômicos através do investimento em ativo intangível; estudos de caso em clubes, verificando quais os objetivos que estes possuem ao investir em atletas, quais os retornos econômicos e financeiros esperados e como se dá o gerenciamento deste recurso, a fim de que ele seja utilizado com a máxima eficiência.

Espera-se então, que o presente estudo tenha contribuído para uma melhor compreensão e discussão do tema em questão, trazendo resposta ao questionamento proposto e alcançado com êxito seus objetivos.

Assim, tem-se fé que apesar de suas limitações o presente trabalho tenha abordado de forma coerente o tema, lançando luz sobre um assunto pouco discutido na esfera nacional e abrindo uma trilha para novos estudos, bem como enriquecendo a literatura ainda escassa sobre o conteúdo proposto para estudo. Afinal, a atividade de pesquisa não tem fim e sempre haverá algo novo a ser descoberto é preciso apenas explorar cada vez mais. 


\section{Referências}

AMIR, E.; LIVNE, G. Accounting, Valuation and Duration of Football Player Contracts. Journal of Business Finance \& Accounting, v. 32, n. 3, p. 3-4 April/May 2005, DOI: 10.1111/j.0306-686X.2005.00604.X

ASSAF NETO; A. Estrutura e análise de balanços: um enfoque econômico-financeiro. 10 ed. São Paulo: Atlas, 2012.

BARNEY, J. Firm Resource and Sustained Competitive Advantage. Journal of Management, v.17, n.1, p. 99-129, 1991, DOI: 10.1177/014920639101700108

BORGES, F.Q. Análise dos impactos socioeconômicos dos royalties minerais do projeto carajás no município de Parauapebas no Estado do Pará (1999 a 2007). 2008. Dissertação (Mestrado em economia). Universidade da Amazônia, Belém, 2008.

BORGES, R.S. Confrontando avaliações: exame nacional de cursos e análise envoltória de dados. Revista Intersaberes, v.1 n. 2, p. 259 - 271, jul-dez 2006.

CARVALHO, F.P.L; BOENTE, D.R.; STEPPAN, A.I.B; MÓL, A.L.R. Eficiência econômico-financeira do setor de energia elétrica brasileiro nos anos de 2010 a 2011. Revista de Informação contábil, Recife, v.8, n.1, p. 1-27, Janeiro a março de 2014.

CARVALHO, L.N.G.; COSTA, P.S.; OLIVEIRA, A.T. Imparment no setor público: particularidades das normas nacionais e internacionais. Revista de Administração pública, Rio de Janeiro, v. 44, n.4, p. 839-876, jul-ago de 2010.

COMITÊ DE PRONUNCIAMENTOS CONTÁBEIS. CPC 04 (R1) - Ativo Intangível. 2010. Disponível em:

$<$ http://static.cpc.mediagroup.com.br/Documentos/187_CPC_04_R1_rev\%2006.pdf $>$ Acesso em: 15 de fev. 2015.

CONSELHO FEDERAL DE CONTABILIDADE. Resolução $\mathbf{n}^{\mathbf{0}} \mathbf{1 . 0 0 5}$, de 15 de Setembro de 2004 - Aprova a NBC T 10.13 - Dos aspectos contábeis específicos em entidades desportivas profissionais. Disponível em:

$<$ http://www.cosif.com.br/mostra.asp?arquivo=rescfc1005nbct1013 $>$ Acesso em: 14 de dez. de 2014.

CONSELHO FEDERAL DE CONTABILIDADE. Resolução n $\mathbf{1 . 4 2 9}$, de 25 de Janeiro de 2013 - Aprova a ITG 2003 - Entidade Desportiva Profissional. Disponível em:

$<$ www.cfc.org.br/sisweb/sre/docs/RES_1429.doc> Acesso em: 14 de dez. de 2014.

CRUZ, S. N.S.R.A.; SANTOS, L.L.; AZEVEDO, G.M.C. Valorização do Direito Esportivo resultante da Formação. Revista de Educação e Pesquisa em Contabilidade. Brasília, v.4, n.1, art. 4, p.60-83, jan-abr 2010, DOI: 10.17524/repec.v4i1.148

DANTAS, M.G. Fatores Determinantes da Eficiência financeira e esportiva de clubes de futebol do Brasil. 2013. Dissertação (Mestrado em Ciências Contábeis). Programa Multiinstitucional e inter-regional de pós-graduação em ciências contábeis - UnB, UFPB, UFRN, Natal, 2013.

DANTAS, M.G.S.; BOENTE, D.R. A Eficiência Financeira e Esportiva dos Maiores Clubes de Futebol Europeus utilizando a Análise envoltória de dados. Revista de Contabilidade e Organizações, v.5, n.13, p. 75-90, 2011, DOI: 10.11606/rco.v5i13.34805

DANTAS, M.G.S.; BOENTE, D.R. A utilização da Análise Envoltória de Dados na Medição de Eficiência dos Clubes Brasileiros de futebol. Revista Contabilidade Vista \& Revista, 
Belo Horizonte, v.23, n.4, p. 101-130, abr/jun, 2012.

DANTAS, M.G.S; MACHADO, M.A.V.; MACEDO, M.A.S. Fatores determinantes da eficiência dos clubes de futebol do Brasil. Advances in Scientific and applied accounting. São Paulo, v.8, n.1, p.113-132, jan/abr de 2015. DOI: 10.14392/asaa.2015080106

DINIZ, Josedilton Alves. Eficiência das transferências intergovernamentais para a educação fundamental de municípios brasileiros. 2012. Tese (Doutorado em Controladoria e Contabilidade: Contabilidade) - Faculdade de Economia, Administração e Contabilidade, Universidade de São Paulo, São Paulo, 2012. doi:10.11606/T.12.2012.tde-26072012-113928

ESPITIA-ESCUER, M.; GARCÍA-CEBRIÁN, L.I. Measurement of the Efficiency of Football Teams in the Champions League. Managerial and Decision Economics, v. 31, p. 373-386, 2010.

ESPN. Estudo de banco: Fla terá maior lucro de 2015; Corinthians, o maior prejuízo. ESPN Online. Publicado em 09 de fev de 2015. Disponível em:

$<$ http://espn.uol.com.br/noticia/482956_estudo-de-banco-fla-tera-maior-lucro-de-2015corinthians-o-maior-prejuizo> Acesso em fev de 2017.

FIGUEIREDO FILHO, D.B.; SILVA JÚNIOR, J.A. Desvendando os Mistérios do Coeficiente de Correlação de Pearson (r). Revista Política Hoje, v. 18, n. 1, 2009. DOI: 10.11606/issn.2237-4485.lev.2014.132346

FINANCIAL ACCOUNTING STANDARDS BOARD n.3 - Reporting Accounting Changes in Interim Financial Statements. December, 1974. Disponível em: http://www.fasb.org/jsp/FASB/Document_C/DocumentPage?cid=1218220126101\&accepted Disclaimer=true $>$ Acesso em jan de 2016.

FITZSIMMONS, J. A.; FITZSIMMONS, M. J. Administração de serviços: operações, estratégia e tecnologia de informação .2. ed. Porto Alegre: Bookman, 2000. 537 p.

FOKER, J. Discussion of Accounting, Valuation and Duration of Football Player Contracts. Journal of Business Finance \& Accounting, v. 32, n. 3/4, 2005. DOI: 0.1111/j.0306686X.2005.00605.x

FORZA, C.; SALVADOR, F. Assessing some distinctive dimensions of performance feedback information in high performing plants, International Journal of Operations \& Production Management, v. 20, n. 3, p.359 - 385, 2000. DOI: 10.1108/01443570010308112

FRANCK, E.; NÜESCH, S.; PIEPER, J. Specific Human Capital as a Source of superior Team Performance. Human capital, v. 63, p. 376-392, 2011. DOI: 10.1111/j.14657295.2010.00360.x

GIACOMELLO, C.P.; OLIVEIRA, R.L. Análise Envoltória de Dados (DEA): Uma proposta para avaliação de desempenho de unidades acadêmicas de uma Universidade. Revista Gestão Universitária na América Latina, Florianópolis, v.7, n.2., p. 130-151, mai. de 2014. DOI: $10.5007 / 1983-4535.2014 \mathrm{v} 7 \mathrm{n} 2 \mathrm{p} 130$

GOMES, E.G.; MELLO, J.C.B.S.; LINS, M.P.E. Redistribuição de inputs e outputs em modelos de análise envoltória de dados com ganhos de soma zero. Pesquisa Operacional, Rio de Janeiro, v. 24, n.2, 2004. DOI: 10.1590/S0101-74382004000200004

GUINDANI, T.P.; SIQUEIRA, F.; PICANÇO, E.; NAVARRO, C. O papel do Marketing Esportivo como Ferramenta geradora de recursos. In: IX Convinbra Administração, 2012 Anais... 2012. Disponível em: 
$<$ http://www.convibra.com.br/upload/paper/2012/37/2012_37_4454.pdf $>$ Acesso em 07 de dez de 2015.

IUDÍCIBUS; S. Análise de Balanços.10 ed. São Paulo: Atlas, 2009.

ITAÚ. Análise Econômico-Financeira dos Clubes de Futebol Brasileiros de 2015. Disponível em: $<$ https://download.uol.com.br/esporte/analise-economico-financeira-dos-clubes-defutebol-brasileiros-de-2015.pdf $>$ Acesso em fev de 2017.

KRETZER, J; MENEZES, E.A. A Importância da Visão Baseada em Recursos na Explicação da Vantagem competitiva. Revista de Economia Mackenzie, v. 4, n. 4, p. 63-87, 2006.

LIMA, M.C. Monografia: a engenharia da Produção Acadêmica. 2 ed. rev. e atualizada. São Paulo: Saraiva, 2008.

LOPES, H.A.; DAVIS, M.D. O Ativo Jogador de Futebol. PENSAR CONTÁBIL, v. 8, n. 33, 2006.

MACEDO, M.A.S.; CASA NOVA, S.P.C.; ALMEIDA, K. Mapeamento e análise bibliométrica da utilização da Análise Envoltória de Dados (DEA) em estudos em contabilidade e administração. Contabilidade, Gestão e Governança. Brasília, v.12, n.3, p. 87-101, set/dez de 2009.

MELLO, J.C.B.S.; MEZA, L.A. GOMES, E.G.; BIONDI NETO. L. Curso de Análise Envoltória de Dados. In: XXXVII Simpósio Brasileiro de Pesquisa Operacional. Gramados, Rio Grande do Sul, 2005. Anais... Gramado, 2012. Disponível em:

$<$ http://www.uff.br/decisao/sbpo2005_curso.pdf $>$. Acesso em 25 de set. 2016

MINTZBERG, H. Trabalho do Executivo: O Folclore e o Fato. Nova Cultural, S.P., 1986.

NASCIMENTO, J.C.H.; NOSSA, V.; BERNARDES, J.R.; SOUSA, W.D. A Eficiência dos maiores clubes de futebol brasileiros: evidências de uma análise longitudinal no período de 2006 a 2011. Revista Contabilidade Vista \& Revista, Belo Horizonte, v. 26, n. 2, p. 137 161, mai./ago. de 2015.

NEVES, J.L. Pesquisa Qualitativa - Características, usos e possibilidades. Caderno de Pesquisa em Administração, São Paulo, v.1, n. 7, 1996.

PEDROSA, A.J.P.; CARVALHO, F.M.P. Análise dos Fundamentos da Teoria Baseada nos recursos. Revista Ibero-Americana de Estratégia, v.13, n.2, abr/jun, 2014.

PEREIRA, A.G.C.; BRUNOZI JÚNIOR, A.C.; KRONBAUER, C.A.; ABRANTES, L.A. Eficiência técnica e desempenho econômico-financeiro dos clubes de futebol brasileiros. Reuna, Belo Horizonte, v.20, n.2, p.115-138, abr/jun de 2015.

PEREZ, M.M.; FAMÁ, R. Ativos Intangíveis e o Desempenho Empresarial. Revista Contabilidade e Finanças - USP. São Paulo, n. 40, p.7 - 24, jan/abr. 2006.

PIRES, G.L. Breve Introdução ao Estudo dos Processos de Apropriação Social do Fenômeno Esporte. Revista da Educação Física/UEM, v.9 n.1, p. 25-34, 1998.

RISALTI, G. VERONA, R. Players' registration rights in the financial statements of the leading Italian clubs. A survey of Inter, Juventus, Lazio, Milan and Roma. Accounting, Auditing \& Accountability Journal, v. 26, n. 1, p. 16-47, 2013. DOI:

$10.1108 / 09513571311285603$

RUTHERFORD, B.A. The social construction of financial statement elements under Private 
Finance Initiative schemes, Accounting, Auditing \& Accountability Journal, v. 16, n. 3, p.372 - 396, 2003. DOI: 10.1108/09513570310482336

SÁ, E.; ZARKO, R. Vasco ainda espera retorno financeiro, e Bernardo vai ter sua última chance. Globo Esporte Online. Disponível em:

$<$ http://globoesporte.globo.com/futebol/times/vasco/noticia/2014/12/vasco-ainda-esperaretorno-financeiro-e-bernardo-vai-ter-sua-ultima-chance.html> Acesso em abr. de 2015

SASSON, J.R.; DOUGLAS, I. A conceptual integration of performance analysis, knowledge management, and technology: from concept to prototype. Journal of Knowledge

Management, v. 10, n. 6, p.81 - 99, 2006. DOI: 10.1108/13673270610709233.

SILVA JÚNIOR, A.S.; SALAZAR, V.S.; FEITOSA, M.G.G. O Clube dos 13 e o novo Cenário do Futebol Brasileiro. Rev. Bras. Ciênc. Esporte, Florianópolis, v. 36, n. 1, p. 103122, jan./mar. 2014. DOI: 10.1590/S0101-32892014000100008.

SILVEIRA, J.Q.; MEZA, L.A.; MELLO, J.C.C.B.S. Identificação de benchmarks e antibenchmarks para companhias aéreas usando modelos DEA e fronteira invertida. Production. v.22, n.4, set./dec. 2012. DOI: 10.1590/S0103-65132011005000004

SONZA, I.B.; KLOECKNER, A Governança Corporativa Influencia a Eficiência das Empresas Brasileiras? Revista Contabilidade e Finanças, São Paulo, v. 25, n. 65, p. 145 160, mai/jun./jul./ago. 2014. DOI: 10.1590/S1519-70772014000200005.

SOUZA, I.G. Os programas de melhoria realmente importam? Uma avaliação em uma empresa de manufatura. 2014. Dissertação (Mestrado em Engenharia da Produção e Sistemas) Universidade do Vale do Rio dos Sinos, São Leopoldo, 2014.

WENERFELT, B. A Resource-Based View of the firm. Strategic Management Journal, v.5, p. 171-180, 1984. DOI: 10.1002/smj.4250050207

ZÜGE, M.; CHAVES NETO, A. Utilização de Métodos Estatísticos Multivariados na Avaliação do Desempenho Empresarial. Revista Paranaense de Desenvolvimento, Curitiba, n. 97, p. 101-112, set/dez de 1999.

APÊNDICE A - DADOS DO ESTUDO TABULADOS

\begin{tabular}{|c|l|l|l|l|l|}
\hline Clube & Variável & \multicolumn{1}{|c|}{$\mathbf{2 0 1 0}$} & \multicolumn{1}{c|}{$\mathbf{2 0 1 1}$} & \multicolumn{1}{c|}{$\mathbf{2 0 1 2}$} & \multicolumn{1}{c|}{$\mathbf{2 0 1 3}$} \\
\hline \multirow{4}{*}{$\begin{array}{c}\text { Atlético } \\
\text { Paranaense }\end{array}$} & INVAI & $1.743 .439,00$ & $890.284,00$ & $2.579 .886,00$ & $-2.952 .714,00$ \\
\cline { 2 - 6 } & REC & $39.110 .053,00$ & $35.978 .892,00$ & $48.415 .537,00$ & $63.417 .949,00$ \\
\cline { 2 - 6 } & FCX & $302.860,00$ & $15.313 .451,00$ & $8.120 .836,00$ & $4.138 .756,00$ \\
\cline { 2 - 6 } & RES & $6.243 .187,00$ & $-4.919 .841,00$ & $122.813 .818,00$ & $-6.497 .075,00$ \\
\hline \multirow{5}{*}{ Botafogo } & INVAI & $19.683 .957,00$ & $15.643 .109,00$ & $-5.504 .363,00$ & $6.084 .297,00$ \\
\cline { 2 - 6 } & REC & $39.089 .522,00$ & $36.313 .360,00$ & $74.675 .743,00$ & $86.479 .000,00$ \\
\cline { 2 - 6 } & FCX & $175.762,00$ & $147.833,00$ & $45.000,00$ & $162.000,00$ \\
\cline { 2 - 6 } & RES & $-29.430 .569,00$ & $166.614 .118,00$ & $-49.280 .000,00$ & $-80.299 .000,00$ \\
\hline \multirow{5}{*}{ Corinthians } & INVAI & $-1.364 .000,00$ & $36.760 .000,00$ & $-3.822 .000,00$ & $6.541 .000,00$ \\
\cline { 2 - 6 } & REC & $142.967 .000,00$ & $207.367 .000,00$ & $286.785 .000,00$ & $222.137 .000,00$ \\
\cline { 2 - 6 } & FCX & $1.145 .000,00$ & $4.003 .000,00$ & $26.598 .000,00$ & $5.210 .000,00$ \\
\cline { 2 - 6 } & RES & $3.477 .000,00$ & $16.636 .000,00$ & $7.538 .000,00$ & $1.016 .000,00$ \\
\hline Criciúma & INVAI & $233.416,00$ & $362.092,00$ & $-323.612,00$ & $-431.186,00$ \\
\hline
\end{tabular}




\begin{tabular}{|c|c|c|c|c|c|}
\hline & REC & $6.807 .160,00$ & $19.800 .633,00$ & $19.963 .924,00$ & $42.423 .695,00$ \\
\hline & $\mathrm{FCX}$ & $581.053,00$ & $5.860 .310,00$ & $1.371 .463,00$ & $4.967 .300,00$ \\
\hline & RES & $-4.003 .737,00$ & $4.470 .829,00$ & $-2.088 .802,00$ & $6.288 .354,00$ \\
\hline \multirow{4}{*}{ Figueirense } & INVAI & $-123.900,00$ & $1.236 .746,00$ & $1.686 .262,00$ & $-14.197,00$ \\
\hline & REC & $11.203 .731,00$ & $25.229 .241,00$ & $36.580 .630,00$ & $17.567 .116,00$ \\
\hline & $\mathrm{FCX}$ & $92.221,00$ & $3.054 .782,00$ & $2.208 .696,00$ & $3.055 .120,00$ \\
\hline & RES & $-7.300 .593,00$ & $-6.769 .278,00$ & $-7.817 .582,00$ & $-19.631 .819,00$ \\
\hline \multirow{4}{*}{ Flamengo } & INVAI & $4.896 .140,00$ & $15.944 .988,00$ & $32.226 .525,00$ & $-46.081 .922,00$ \\
\hline & REC & $105.908 .999,00$ & $152.686 .698,00$ & $158.672 .958,00$ & $234.272 .495,00$ \\
\hline & FCX & $801.198,00$ & $1.730 .830,00$ & $568.909,00$ & $12.034 .398,00$ \\
\hline & RES & $-21.709 .519,00$ & $-12.409 .994,00$ & $-62.451 .879,00$ & $-19.512 .492,00$ \\
\hline \multirow{4}{*}{ Fluminense } & INVAI & $-1.083 .000,00$ & $2.627 .000,00$ & $26.793 .000,00$ & $-15.317 .000,00$ \\
\hline & REC & $57.608 .000,00$ & $56.681 .000,00$ & $92.441 .000,00$ & $100.034 .000,00$ \\
\hline & FCX & $2.840 .000,00$ & $805.000,00$ & $4.625 .000,00$ & $28.653 .000,00$ \\
\hline & RES & $-41.980 .000,00$ & $-34.135 .000,00$ & $-3.716 .000,00$ & $-3.308 .000,00$ \\
\hline \multirow{4}{*}{ Goiás } & INVAI & - & $-250.000,00$ & $-713.246,30$ & $1.909 .378,88$ \\
\hline & REC & $26.077 .671,00$ & $12.995 .106,00$ & $42.573 .606,23$ & $44.901 .565,11$ \\
\hline & $\mathrm{FCX}$ & $105.864,00$ & $105.387,00$ & $9.051 .718,30$ & $259.243,61$ \\
\hline & RES & $-10.690 .334,00$ & $-18.328 .034,00$ & $1.414 .451,24$ & $-7.493 .428,43$ \\
\hline \multirow{4}{*}{ Grêmio } & INVAI & $-1.427 .000,00$ & $15.243 .000,00$ & $-8.385 .554,00$ & $27.559 .554,00$ \\
\hline & REC & $55.559 .000,00$ & $59.094 .000,00$ & $92.787 .866,00$ & $88.678 .000,00$ \\
\hline & $\mathrm{FCX}$ & $667.000,00$ & $2.608 .000,00$ & $8.873 .000,00$ & $5.484 .000,00$ \\
\hline & RES & $-29.342 .000,00$ & $-20.966 .000,00$ & $28.182 .000,00$ & $-51.487 .000,00$ \\
\hline \multirow{4}{*}{ Internacional } & INVAI & $-602.360,00$ & $18.856 .290,00$ & $-7.750 .403,00$ & $10.409 .743,00$ \\
\hline & REC & $60.447 .810,00$ & $88.010 .302,00$ & $127.052 .760,00$ & $90.195 .385,00$ \\
\hline & $\mathrm{FCX}$ & $16.940 .690,00$ & $30.848 .907,00$ & $14.955 .051,00$ & $5.055 .070,00$ \\
\hline & RES & $-2.636 .529,00$ & $-23.382 .042,00$ & $11.045 .455,00$ & $-952.186,00$ \\
\hline \multirow{4}{*}{ Náutico } & INVAI & - & $183.928,00$ & $-341.041,00$ & $-411.628,00$ \\
\hline & REC & $9.800 .983,00$ & $14.891 .760,00$ & $37.297 .147,00$ & $39.616 .592,00$ \\
\hline & $\mathrm{FCX}$ & $142.879,00$ & $216.547,00$ & $892.969,00$ & $400.818,00$ \\
\hline & RES & $-9.506 .635,00$ & $-1.643 .179,00$ & $-392.993,00$ & $-721.320,00$ \\
\hline \multirow{4}{*}{ Palmeiras } & INVAI & $27.757 .000,00$ & $-9.468 .000,00$ & $49.433 .000,00$ & $-34.623 .000,00$ \\
\hline & REC & $78.879 .000,00$ & $103.426 .000,00$ & $136.226 .000,00$ & $127.119 .000,00$ \\
\hline & $\mathrm{FCX}$ & $4.298 .000,00$ & $10.713 .000,00$ & $1.071 .000,00$ & $3.866 .000,00$ \\
\hline & RES & $\begin{array}{l}- \\
113.204 .000,00 \\
\end{array}$ & $-22.760 .000,00$ & $31.864 .000,00$ & $-22.621 .000,00$ \\
\hline \multirow{4}{*}{ Ponte preta } & INVAI & $-22.217 .475,00$ & $-203.903,00$ & $13.439 .043,00$ & $11.363 .023,00$ \\
\hline & REC & $3.268 .472,00$ & $9.764 .982,00$ & $18.444 .589,00$ & $28.535 .551,00$ \\
\hline & FCX & $32.930,00$ & $181.846,00$ & $86.559,00$ & $22.372,00$ \\
\hline & RES & $-9.846 .064,00$ & $-12.633 .151,62$ & $-16.824 .053,00$ & $1.353 .047,00$ \\
\hline \multirow{4}{*}{ Portuguesa } & INVAI & $-2.402 .000,00$ & $-3.133 .000,00$ & $2.752 .000,00$ & $-799.000,00$ \\
\hline & REC & $13.804 .000,00$ & $17.999 .000,00$ & $29.122 .000,00$ & $28.915 .000,00$ \\
\hline & FCX & $40.000,00$ & $65.000,00$ & $90.000,00$ & $221.000,00$ \\
\hline & RES & $-6.663 .000,00$ & $-4.438 .000,00$ & $1.454 .000,00$ & $-27.496000,00$ \\
\hline
\end{tabular}


Análise de desempenho na geração de benefícios econômicos dos clubes de futebol brasileiros: o uso do atleta como recurso estratégico e ativo intangível

\begin{tabular}{|c|l|l|l|l|l|}
\hline \multirow{5}{*}{ Santos } & INVAI & $20.164 .837,00$ & $4.866 .000,00$ & $52.494 .000,00$ & $7.632 .000,00$ \\
\cline { 2 - 6 } & REC & $81.677 .000,00$ & $139.690 .000,00$ & $156.988 .000,00$ & $71.533 .000,00$ \\
\cline { 2 - 6 } & FCX & $518.000,00$ & $378.000,00$ & $565.000,00$ & $432.000,00$ \\
\cline { 2 - 6 } São Caetano & RES & $-8.653 .000,00$ & $7.393 .000,00$ & $14.590 .000,00$ & $-40.621 .000,00$ \\
\hline \multirow{5}{*}{ São Paulo } & INVAI & $-729.853,00$ & $1.249 .916,00$ & $2.985 .270,00$ & $4.177 .723,00$ \\
\cline { 2 - 6 } & REC & $15.810 .914,00$ & $23.066 .400,00$ & $30.937 .367,00$ & $36.784 .520,00$ \\
\cline { 2 - 6 } & FCX & $1.972 .938,00$ & $446.143,00$ & $48.663,00$ & $1.009 .392,00$ \\
\cline { 2 - 6 } & RES & $-1.470 .889,00$ & $-761.881,00$ & $-3.300 .255,00$ & $-3.581 .195,00$ \\
\hline & INVAI & $2.453 .000,00$ & $39.301 .000,00$ & $95.172 .000,00$ & $-2.320 .000,00$ \\
\cline { 2 - 6 } & REC & $96.118 .000,00$ & $119.275 .000,00$ & $157.740 .000,00$ & $138.823 .000,00$ \\
\cline { 2 - 6 } & FCX & $10.073 .000,00$ & $15.993 .000,00$ & $23.677 .000,00$ & $15.152 .000,00$ \\
\cline { 2 - 6 } & RES & $454.000,00$ & $220.000,00$ & $826.000,00$ & $23.524 .000,00$ \\
\hline \multirow{5}{*}{ Vasco da Gama } & INVAI & $7.194 .000,00$ & $6.527 .000,00$ & $14.661 .000,00$ & $2.624 .000,00$ \\
\cline { 2 - 6 } & REC & $61.893 .997,00$ & $102.090 .260,00$ & $98.829 .763,00$ & $107.295 .576,00$ \\
\cline { 2 - 6 } & FCX & $2.319 .612,00$ & $1.310 .353,00$ & $495.666,00$ & $868.494,00$ \\
\cline { 2 - 6 } & RES & $-17.759 .946,00$ & $3.414 .564,00$ & $-143.919,00$ & $-3.510 .800,00$ \\
\hline
\end{tabular}

